\title{
Density Functional Vertical Self-Consistent Reaction Field Theory for Solvatochromism Studies of Solvent-Sensitive Dyes
}

\author{
Tiqing Liu, ${ }^{*}, \uparrow$ Wen-Ge Han, ${ }^{*, \dagger}$ Fahmi Himo, ${ }^{\dagger, \|}$ G. Matthias Ullmann, ${ }^{\dagger, \perp}$ Donald Bashford, ${ }^{\dagger, \#}$ \\ Alexei Toutchkine, $\$$ Klaus M. Hahn,,$*$ and Louis Noodleman*, $\uparrow$ \\ Department of Molecular Biology, TPC-15, and Department of Cell Biology, CB 164, \\ The Scripps Research Institute, 10550 North Torrey Pines Road, La Jolla, California 92037 \\ Received: September 10, 2003; In Final Form: January 23, 2004
}

\begin{abstract}
On the basis of the Franck-Condon principle, a density functional vertical self-consistent reaction field (VSCRF) solvation model for vertical excitation and emission processes is established. The principles and implementation of the VSCRF model are presented. The predicted blue shifts of the vertical excitation energies of diazines in different solvents from $n$-heptane to water solutions are compared with the corresponding time dependent density functional calculations and are in very good agreement with experiment. We have also applied this method to predict the blue shifts and the vertical excitation and emission energies of Brooker's merocyanine dye with increasing solvent polarities from $\mathrm{CHCl}_{3}$ to $\mathrm{H}_{2} \mathrm{O}$ solutions. Overall, our calculations predicted the relative excitation and emission energy orderings for Brooker's merocyanine in different solvents with different polarities. Also, the calculated Stokes shift is fairly well represented for different solvents, and the calculations correctly show that the absorption energies have a much stronger solvent dependence than the emission energies. The importance of both relaxation of the molecular structures and consideration of explicit $\mathrm{H}$-bonding $\mathrm{H}_{2} \mathrm{O}$ and $\mathrm{CH}_{3} \mathrm{OH}$ molecules in water and methanol solvents in predicting the solvatochromic shifts is also discussed.
\end{abstract}

\section{Introduction}

It is well-known that the UV/visible absorption and emission spectra (positions, intensities, and shapes) of chemical compounds are usually influenced by the surrounding medium and solvents. This results from the solute-solvent interactions (including the ion-dipole, dipole-dipole, dipole-induced dipole, and $\mathrm{H}$-bonding interactions, etc.) which tend to change the geometries, charge distributions, and therefore the excitation and emission energies of the absorbing and fluorescent species. ${ }^{1}$

The term solvatochromism is used to describe the shift of an UV or visible absorption band in solvents of different polarities. Dye molecules with strong solvatochromic character have been used as probes in the study of micelle/solution interfaces, model liquid membranes, and microemulsions and phospholipid bilayers, applied in analytical chemistry, and used for indicating solvent polarity (see ref 1 and references therein). Very recently, solvatochromic effects (and also the solvent dependency of fluorescence) have been used for sensing protein activity and protein-protein interactions in living cells. ${ }^{2-5}$ For choosing and making new dyes for different purposes, it would be valuable to first predict the optical properties of the dye molecules as a guide for experimental synthesis and measurements. In this

\footnotetext{
* Corresponding authors. E-mail: liu@chemistry.montana.edu, wengehan@scripps.edu, and lou@scripps.edu. Fax: (858) 784-8896.

Department of Molecular Biology, The Scripps Research Institute.

$\doteqdot$ Department of Cell Biology, The Scripps Research Institute.

$\S$ Current address: Department of Chemistry and Biochemistry, Montana State University, Bozeman, MT 59717.

"Current address: Royal Institute of Technology, SCFAB, Department of Biotechnology, Theoretical Chemistry, S-106 91 Stockholm, Sweden.

$\perp$ Current address: Structural Biology/Bioinformatics. University of Bayreuth, Universitätsstr. 30, BGI, 95447 Bayreuth, Germany.

\# Current address: Hartwell Center, St. Jude Children's Research Hospital, 332 N. Lauderdale St., Memphis, TN 38105.
}

paper, we present a density functional vertical self-consistent reaction field (VSCRF) theory to predict the vertical excitation and emission energies, focusing particularly on the solvatochromic shifts of solvent-sensitive dyes with increasing solvent polarity.

According to the Franck-Condon principle, ${ }^{6}$ during the optical absorption (and emission) process, there is only electronic relaxation of the solute and solvent molecules, since the orientational relaxation of the whole system cannot occur on this fast time scale. In the past decades, many efforts have been made in seeking the theoretical treatment of solvent effects on electronic spectroscopy. ${ }^{7-35}$ Both continuum solvent models and the use of explicit solvent molecules in combination with continuum solvent models are increasingly popular in this area. ${ }^{34,36-42}$ Most of the theoretical work in computing solvent shifts on molecular excitation energies in different solvents has been done at the semiempirical level, such as AM1, PM3, and INDO. Semiempirical methods are normally much faster than $a b$ initio calculations and have achieved considerable success in predicting the electronic and geometric properties for different systems. However, different semiempirical methods may produce very different results. ${ }^{21}$ The parameters which were set up for one molecule may not be suitable for another system, ${ }^{24}$ and some of these methods also suffer from the weakness of properly describing the H-bonding interactions, ${ }^{21}$ which are very important to be considered in predicting the solute excitation and emission energies in protic solvents. ${ }^{31,43}$ Very recently, solvent continuum models (PCM, polarizable continuum) for predicting the vertical electronic transitions have been established at the time dependent density functional theory (TDDFT) ${ }^{44}$ level. ${ }^{29-35}$ Calculations on the $n \rightarrow \pi^{*}$ transition energies of diazines performed by Mennucci ${ }^{31}$ and Cossi and Barone ${ }^{34}$ have shown results which are in very good agreement with the 
experiments. However, calculations with TDDFT are still not straightforward in the optimization of geometries on the excited state surfaces for emission processes. It is also not clear how TDDFT can be applied if the excitation is from or the emission is to a diradical broken-symmetry state (like the ground state surface of twisted stilbene). ${ }^{45}$ In the present work, we systematically develop a density functional vertical self-consistent reaction field (VSCRF) solvation model with $\triangle$ SCF methodology, ${ }^{43-52}$ suitable for both absorption and emission, and apply this to diazines and to Brooker's merocyanine. Our applications of this method to other solvent-sensitive fluorescent dyes have recently appeared. ${ }^{43}$

DFT methods have been widely used to study the electronic and geometric properties of different organic and inorganic systems. ${ }^{46-52}$ DFT GGA (generalized gradient approximation) functionals are able to predict reasonable $\mathrm{H}$-bonding properties. ${ }^{53}$ For calculating the emission energies, one has to obtain the relaxed geometries of the chromophore on the excited state surface in different solvents. This can be easily done with the $\triangle$ SCF method using the Amsterdam density functional program package. ${ }^{54}$ This also makes our VSCRF method easily applicable to study the fluorescence band shift with increasing solvent polarity.

Our implementation of the VSCRF method is based on our original self-consistent reaction field (SCRF) development, ${ }^{55-57}$ where the solute molecule is computed by density functional theory in the presence of a solvent reaction field. The reaction field is evaluated from a finite-difference solution to the Poisson-Boltzmann (PB) equation, and self-consistency between the reaction field and the electronic structure of the solute is achieved by iteration. We will call this full SCRF method the SCRF(FDPB) method hereafter (FDPB = finite-difference Poisson-Boltzmann algorithm). The SCRF(FDPB) calculation applied to a solute geometry allows the electronic structure relaxation in both the solute and the solvent and, implicitly, the orientational (geometry) relaxation of the solvent. Once the $\mathrm{SCRF}(\mathrm{FDPB})$ calculation on the ground state $\left(\mathrm{S}_{0}\right)$ (or the first excited singlet state $\left(\mathrm{S}_{1}\right)$ ) is achieved, the VSCRF procedure on the excited state (or the ground state) allows only the electronic structure reorganization for both the solute and the solvent, and the vertical excitation (or emission) in solution is then obtained. In common with our SCRF(FDPB) work, the VSCRF method is readily extended to more complex combined protein-solvent environments, and the first applications of this to photoactive proteins have been completed. ${ }^{58,59}$

In the next section, we will present the VSCRF methodology. Related methods with $a b$ initio Hartree-Fock theory were developed by Liu et al. ${ }^{27,28}$ and with semiempirical methods (INDO/S) were developed by Karelson et al. ${ }^{17 \mathrm{a}}$ The electrostatic/ dielectric theory framework that we developed is similar in approach to the work of Sharp's ${ }^{60}$ standard electrostatics theory. The computational details will be given in section 3 . Then, the applications will be given in section 4 . For comparison with recent TDDFT calculations, ${ }^{34}$ we will first apply our method to predict the solvatochromic shifts of diazines in several solvents from $n$-heptane to water solutions, where the importance of H-bonding effects will also be shown. Then, calculations on Brooker's merocyanine dye (4'-hydroxy-l-methylstilbazolium betaine) will be discussed. Brooker's merocyanine is a typical solvent-sensitive dye with dramatic blue shifts with increasing solvent polarity. ${ }^{11,12,20-22,61-65}$ Very recently, Baraldi et al. reported for the first time the emission energies of this dye in different solvents. ${ }^{24}$ The emission bands also show blue shifts with increasing solvent polarity. However, the shifts are not as large as those in the absorption process. These authors also performed calculations using the "solvation-CS INDO" method to predict the blue shifts of both the absorption and emission bands of this molecule in different solutions. They used the polarity factor $k(\epsilon)$ as a variable to represent the polarities of the solvents. The solute geometry, however, was unchanged in their calculations in different solvents. Also, no explicit $\mathrm{H}$ bonding interactions were considered in protic solvents. Here, we will first see if our SCRF/VSCRF(FDPB) calculations predict an improved absorption band shift for Brooker's merocyanine from $\mathrm{CHCl}_{3}$ to $\mathrm{H}_{2} \mathrm{O}$ solutions, and we will see how important geometry relaxation and the inclusion of the explicit $\mathrm{H}$-bonding interactions are in predicting this shift. Then, calculations on the excitation and emission energies of Brooker's merocyanine in several other solvents will be presented.

\section{Principles}

The model system consists of a solute molecule, which is to be treated quantum mechanically, residing in a cavity within a continuum dielectric medium, which represents the solvent. During a vertical excitation process, the electronic distribution, including both the DFT-modeled electron density and the electronic polarization of the medium, is altered, while, in accordance with the Franck-Condon principle, the nuclear geometry of the solute and the orientational polarization of the dielectric medium are unchanged. A formalism that separates the energetics of the fast (electronic) part of the dielectric response from the equilibrium response is therefore needed.

We now begin with the absorption process to describe the methodology. The energetics of the ground state charge distribution have been outlined elsewhere ${ }^{57,66}$ but are summarized here to establish the context and the notation. Consider the process of building up the ground state charge distribution, $\rho_{\mathrm{i}}$, inside the cavity from nothing by infinitesimal increments $\delta \rho$. At some intermediate stage where the distribution so far is $\rho$, and the potential it gives rise to is $\phi$, the incremental work of adding the next increment, $\delta \rho$, is $\delta W=\int \phi \delta \rho \mathrm{d}^{3} x$. The $\rho$ dependence of $\phi$ is assumed to be governed by the Poisson equation, so it can be conveniently expressed by the Green function, $G_{\mathrm{eq}}\left(x, x^{\prime}\right)$, which satisfies

$$
\nabla \epsilon(x) \nabla G_{\mathrm{eq}}\left(x, x^{\prime}\right)=-4 \pi \delta\left(x-x^{\prime}\right)
$$

where the differentiation acts on the $x$ dependence of $G, \delta$ is the (3-dimensional) Dirac delta function, and $\epsilon(x)$ has the value 1 inside the solute cavity and the equilibrium (or static) dielectric constant value, $\epsilon_{\mathrm{eq}}$, outside $\left(\epsilon_{\mathrm{eq}} \approx 80\right.$ in $\left.\mathrm{H}_{2} \mathrm{O}\right)$. In other words $G\left(x, x^{\prime}\right)$ is the potential at $x$ that would result from placing a unit point charge at $x^{\prime}$. The equilibrium potential due to an arbitrary charge distribution $\rho$ is then $\phi(x)=\int G\left(x, x^{\prime}\right) \rho\left(x^{\prime}\right) \mathrm{d}^{3} x^{\prime}$. The incremental work can then be written by

$$
\delta W=\iint G_{\text {eq }}\left(x, x^{\prime}\right) \rho\left(x^{\prime}\right) \delta \rho(x) \mathrm{d}^{3} x \mathrm{~d}^{3} x^{\prime}
$$

Functional integration from $\rho=0$ to $\rho=\rho_{\text {i }}$ gives the classical electrostatic work of forming the initial charge distribution as

$$
\begin{aligned}
W_{\mathrm{i}}=1 / 2 \iint G_{\text {eq }}\left(x, x^{\prime}\right) \rho_{\mathrm{i}}\left(x^{\prime}\right) \rho_{\mathrm{i}}(x) \mathrm{d}^{3} x \mathrm{~d}^{3} x^{\prime}= \\
1 / 2 \int \phi_{\mathrm{i}, \mathrm{eq}}(x) \rho_{\mathrm{i}}(x) \mathrm{d}^{3} x
\end{aligned}
$$

In practical calculations, the DFT codes calculate the Coulombic plus exchange correlation energies of the electron density and nuclear charges along with the electronic kinetic energy, while a Poisson solver provides electrostatic potentials but not Green functions. Therefore, some transformations of eq 3 are 
needed. The Green functions can always be written as the sum of a Coulomb term and a reaction field term:

$$
G\left(x, x^{\prime}\right)=\left|x-x^{\prime}\right|^{-1}+G^{(\mathrm{r})}\left(x, x^{\prime}\right)
$$

where $G^{(\mathrm{r})}$ is free of singularities and discontinuities in the cavity interior. Substituting this form into eq 3 gives

$$
\phi_{\mathrm{i}, \mathrm{eq}}(x)=\int \frac{\rho_{\mathrm{i}}\left(x^{\prime}\right)}{\left|x-x^{\prime}\right|} \mathrm{d}^{3} x^{\prime}+\phi_{\mathrm{i}, \mathrm{eq}}^{\mathrm{r}}(x)
$$

where

$$
\phi_{\mathrm{i}, \mathrm{eq}}^{\mathrm{r}}(x)=\int G_{\mathrm{eq}}^{\mathrm{r}}\left(x, x^{\prime}\right) \rho_{\mathrm{i}}\left(x^{\prime}\right) \mathrm{d}^{3} x^{\prime}
$$

and therefore

$$
\begin{aligned}
& W_{\mathrm{i}}=W_{\mathrm{i}}^{\text {coul }}(\text { tot })+W_{\mathrm{i}}^{\mathrm{r}}=1 / 2 \iint \frac{\rho_{\mathrm{i}}\left(x^{\prime}\right) \rho_{\mathrm{i}}(x)}{\left|x-x^{\prime}\right|} \mathrm{d}^{3} x \mathrm{~d}^{3} x^{\prime}+ \\
& { }^{1} / 2 \iint G_{\mathrm{eq}}^{\mathrm{r}}\left(x, x^{\prime}\right) \rho_{\mathrm{i}}\left(x^{\prime}\right) \rho_{\mathrm{i}}(x) \mathrm{d}^{3} x \mathrm{~d}^{3} x^{\prime}
\end{aligned}
$$

Here, $\rho_{\mathrm{i}}$ includes both the electron and the nuclear charge densities (and so will $\rho_{\mathrm{f}}$ for the final state), since the solvent responds to the total charge density of the initial state.

Including the remaining quantum terms for the kinetic energy, $T_{\mathrm{i}}$, and exchange-correlation energy, $E_{\mathrm{XC}}(\mathrm{i})$, and separating $W_{i}^{\text {coul }}$ (tot) into nuclear-electron attraction, $V_{\mathrm{Ne}}(\mathrm{i})$, nuclearnuclear repulsion, $V_{\mathrm{NN}}(\mathrm{i})$, and electronic repulsion, $W_{\mathrm{i}}^{\text {coul }}(\mathrm{ee})$, terms $\left(W_{\mathrm{i}}^{\text {coul }}(\right.$ tot $\left.)=V_{\mathrm{Ne}}(\mathrm{i})+V_{\mathrm{NN}}(\mathrm{i})+W_{\mathrm{i}}^{\text {coul }}(\mathrm{ee})\right)$ give the following for the ground state free energy, $G_{0}^{\mathrm{i}}$, for the solvated ground state density, $\rho_{\mathrm{i}}$ :

$$
\begin{aligned}
& G_{0}^{\mathrm{i}}\left(\rho_{\mathrm{i}}(\text { solvated })\right)=T_{\mathrm{i}}+V_{\mathrm{Ne}}(\mathrm{i})+V_{\mathrm{NN}}(\mathrm{i})+E_{\mathrm{XC}}(\mathrm{i})+ \\
& W_{\mathrm{i}}^{\text {coul }}(\text { ee })+W_{\mathrm{i}}^{\mathrm{r}}=E_{0}^{\mathrm{i}}\left(\rho_{\mathrm{i}}\right)+{ }^{1} / 2 \int \rho_{\mathrm{i}}(x) \phi_{\mathrm{i}, \mathrm{eq}}^{\mathrm{r}}(x) \mathrm{d}^{3} x
\end{aligned}
$$

where $E_{0}^{\mathrm{i}}\left(\rho_{\mathrm{i}}\right)=T_{\mathrm{i}}+V_{\mathrm{Ne}}(\mathrm{i})+V_{\mathrm{NN}}(\mathrm{i})+E_{\mathrm{XC}}(\mathrm{i})+W_{\mathrm{i}}^{\text {coul }}(\mathrm{ee})$ is the electronic energy and $W_{\mathrm{i}}^{\mathrm{r}}=1 / 2 \int \rho_{\mathrm{i}}(x) \phi_{\mathrm{i}, \mathrm{eq}}^{\mathrm{r}}(x) \mathrm{d}^{3} x$ is the direct reaction field energy. The nuclear repulsion term is the same for the ground and excited states, since the geometry is the same for a vertical excitation, and therefore, this subtracts out for the vertical excitation energy. In the present work, we have neglected both the zero point vibrational energy and the thermal energy contributions to the solute free energy in both the ground and excited states.

Now consider the rapid change of the charge distribution in the cavity from $\rho_{\mathrm{i}}$ to $\rho_{\mathrm{f}}$, which can be regarded as the appearance of an additional charge distribution, $\Delta \rho=\rho_{\mathrm{f}}-\rho_{\mathrm{i}}$. The rapidity of the process is such that only the optical (electronic) component of the medium's dielectric response is able to follow it. At an intermediate stage of this process where the extra charge so far is $\Delta \rho^{\prime}$, the additional potential is $\Delta \phi^{\prime}=\int G_{\mathrm{op}}\left(x, x^{\prime}\right) \Delta \rho^{\prime}\left(x^{\prime}\right)$ $\mathrm{d}^{3} x^{\prime}$, where $G_{\text {op }}$ is the solution of an equation similar to eq 1 , except that $\epsilon$ outside the cavity now takes on the optical dielectric constant value, $\epsilon_{\mathrm{op}}=n^{2} \approx 2$ (where $n$ is the index of refraction). The incremental electrostatic work expression is now

$$
\begin{aligned}
& \delta W=\iint G_{\mathrm{eq}}\left(x, x^{\prime}\right) \rho_{\mathrm{i}}\left(x^{\prime}\right) \delta \rho(x) \mathrm{d}^{3} x \mathrm{~d}^{3} x^{\prime}+ \\
& \qquad \int G_{\mathrm{op}}\left(x, x^{\prime}\right) \Delta \rho^{\prime}\left(x^{\prime}\right) \delta \rho(x) \mathrm{d}^{3} x \mathrm{~d}^{3} x^{\prime}
\end{aligned}
$$

where the first term is the work done against the pre-existing equilibrium potential, $\phi_{\mathrm{i}, \mathrm{eq}}(x)$, and the second is the work done against the potential arising from the new charge so far, $\Delta \rho^{\prime}$. Functional integration from zero to the full change, $\Delta \rho$, gives the electrostatic work done during the excitation process

$$
\begin{array}{r}
W_{\mathrm{ex}}^{\mathrm{if}}=\iint G_{\mathrm{eq}}\left(x, x^{\prime}\right) \rho_{\mathrm{i}}\left(x^{\prime}\right) \Delta \rho(x) \mathrm{d}^{3} x \mathrm{~d}^{3} x^{\prime}+ \\
1 / 2 \iint G_{\mathrm{op}}\left(x, x^{\prime}\right) \Delta \rho\left(x^{\prime}\right) \Delta \rho(x) \mathrm{d}^{3} x \mathrm{~d}^{3} x^{\prime}
\end{array}
$$

Now substituting eq 4 into eq 10 and including changes in other energy terms give

$$
\begin{aligned}
& \Delta G_{\mathrm{ex}}^{\mathrm{if}}=\left[1 / 2 \iint \frac{\rho_{\mathrm{f}}^{\mathrm{el}}\left(x^{\prime}\right) \rho_{\mathrm{f}}^{\mathrm{el}}(x)-\rho_{\mathrm{i}}^{\mathrm{el}}\left(x^{\prime}\right) \rho_{\mathrm{i}}^{\mathrm{el}}(x)}{\left|x-x^{\prime}\right|} \mathrm{d}^{3} x \mathrm{~d}^{3} x^{\prime}+\Delta T+\right. \\
&\left.\Delta V_{\mathrm{Ne}}+\Delta E_{\mathrm{XC}}\right]+\left[\iint G_{\mathrm{eq}}^{(\mathrm{r})}\left(x, x^{\prime}\right) \rho_{\mathrm{i}}\left(x^{\prime}\right) \Delta \rho(x) \times\right. \\
&\left.\mathrm{d}^{3} x \mathrm{~d}^{3} x^{\prime}+{ }^{1} / 2 \iint G_{\mathrm{op}}^{(\mathrm{r})}\left(x, x^{\prime}\right) \Delta \rho\left(x^{\prime}\right) \Delta \rho(x) \mathrm{d}^{3} x \mathrm{~d}^{3} x^{\prime}\right]
\end{aligned}
$$

where we have made use of the fact that $2 \rho_{\mathrm{i}} \Delta \rho+\Delta \rho \Delta \rho=\rho_{\mathrm{f}} \rho_{\mathrm{f}}$ $-\rho_{\mathrm{i}} \rho_{\mathrm{i}}$, where $\rho_{\mathrm{i}}=\rho_{\mathrm{i}}^{\mathrm{el}}+\rho_{\mathrm{i}}^{\mathrm{N}}$ and $\rho_{\mathrm{f}}=\rho_{\mathrm{f}}^{\mathrm{el}}+\rho_{\mathrm{f}}^{\mathrm{N}}$. For both states $\mathrm{i}$ and $\mathrm{f}$, the total charge density is the sum of the electronic (el) and nuclear $(\mathrm{N})$ densities. For fixed nuclei, $\rho_{\mathrm{i}}^{\mathrm{N}}=\rho_{\mathrm{f}}^{\mathrm{N}}$, so $\Delta \rho_{\mathrm{if}}=$ $\Delta \rho_{\text {if }}^{\text {el }}$ for vertical excitations. The reaction potential due to some distribution $\rho$ in the cavity is $\phi^{(\mathrm{r})}=\int G^{(\mathrm{r})}\left(x, x^{\prime}\right) \rho\left(x^{\prime}\right) \mathrm{d}^{3} x^{\prime}$. In practice, such a reaction potential can be obtained by solving the Poisson equation for the particular charge and dielectric distribution in question and subtracting off a vacuum Coulomb potential for the same charge distribution. In terms of reaction field potentials, the free energy expression for the vertical excitation energy (based on eq 11) becomes

$$
\begin{array}{r}
\Delta G_{\mathrm{ex}}^{\mathrm{if}}=E_{0}^{\mathrm{f}}-E_{0}^{\mathrm{i}}+{ }^{1} / 2 \int\left[2 \phi_{\mathrm{i}, \mathrm{eq}}^{(\mathrm{r})}(x)+\Delta \phi_{\mathrm{op}}^{(\mathrm{r})}(x)\right] \Delta \rho_{\mathrm{if}}(x) \mathrm{d}^{3} x= \\
\Delta E_{0}+\Delta G_{\mathrm{pot}}+\Delta G_{\mathrm{res}}
\end{array}
$$

where $E_{0}^{\mathrm{i}}$ and $E_{0}^{\mathrm{f}}$ are the solute electronic energies of the initial and final charge distributions, respectively, $\phi_{\mathrm{i}, \mathrm{eq}}^{(\mathrm{r})}$ is the reaction potential of $\rho_{\mathrm{i}}$ obtained from the Poisson equation solution with the dielectric outside the cavity set to $\epsilon_{\mathrm{eq}}$, and $\Delta \phi_{\mathrm{op}}^{(\mathrm{r})}$ is the reaction potential of $\Delta \rho$ obtained with the outside dielectric set to $\epsilon_{\mathrm{op}}$. Now the vertical excitation energy, $\Delta G_{\mathrm{ex}}^{\mathrm{if}}$, is described by the sum of three terms: (1) $\Delta E_{0}=E_{0}^{\mathrm{f}}-E_{0}^{\mathrm{i}}$, which is the increase in the solute electronic energy upon excitation; (2) the potential term, $\Delta G_{\text {pot }}=\int \phi_{\mathrm{i}, \mathrm{eq}}^{(\mathrm{r})}(x) \Delta \rho_{\mathrm{if}}(x) \mathrm{d}^{3} x$, which describes the change of the reaction field energy caused by the reorganization of the solute electronic structure; and (3) the response term, $\Delta G_{\text {res }}=1 / 2 \int \Delta \phi_{\text {op }}^{(\mathrm{r})}(x) \Delta \rho_{\text {if }}(x) \mathrm{d}^{3} x$, which is the change of the free energy due to the electron relaxation in the solvent.

Alternatively, the final vertical excited state energy including all contributions is

$$
\begin{array}{r}
G_{\mathrm{ex}}^{\mathrm{f}}=E_{0}^{\mathrm{f}}+{ }^{1} / 2 \int \phi_{\mathrm{i}, \mathrm{eq}}^{(\mathrm{r})}(x) \rho_{\mathrm{i}}(x) \mathrm{d}^{3} x+{ }^{1} / 2 \int\left[2 \phi_{\mathrm{i}, \mathrm{eq}}^{(\mathrm{r})}(x)+\right. \\
\left.\Delta \phi_{\mathrm{op}}^{(\mathrm{r})}(x)\right] \Delta \rho_{\mathrm{if}}(x) \mathrm{d}^{3} x
\end{array}
$$

which then gives the vertical excitation energy,

$$
\Delta G_{\mathrm{ex}}^{\mathrm{if}}=G_{\mathrm{ex}}^{\mathrm{f}}-G_{0}^{\mathrm{i}}
$$

as in eq 12. Applying the variational principle to $\rho_{\mathrm{f}}$ gives the final reaction field potential, $\phi_{\mathrm{f}}^{(\mathrm{r})}=\phi_{\mathrm{i}, \mathrm{eq}}^{(\mathrm{r})}+\Delta \phi_{\mathrm{op}}^{(\mathrm{r})}$.

For the emission process, the initial state (i) is the relaxed excited state and the final state (f) is then the vertical ground state. The emission energy, $\Delta G_{\mathrm{em}}^{\mathrm{if}}$, can also be described, as in eq 12 . 
Our mathematical formalism is quite simple compared to that in important prior work on this problem; one can compare eqs 11-13 and their derivations with those of Aguilar et al. (eq $35)^{13}$ and $\mathrm{Li}$ et al. (eqs 20-21 and 25-28). ${ }^{14}$ The physical foundation also clearly involves (1) application of Gauss's law in dielectric media for the solvent reaction field potential due to the ground state charge distribution, and the "fast electronic" solvent response reaction field potential due to the excitation charge density; (2) the assumed validity of the linear response (see eqs 1, 2, 3, and 9); (3) the electrostatic work on excitation against the pre-existing potential $\left(\Delta G_{\mathrm{pot}}\right)$, and against the varying optical potential $\left(\Delta G_{\text {res }}\right)$, and the corresponding separation of time scales; and (4) the use of the variational principle on both the equilibrium $\left(\rho_{\mathrm{i}}\right)$ and nonequilibrium states $\left(\rho_{\mathrm{f}}\right)$. Despite substantial differences in notation and numerical methods (FDPB vs a surface charge method ${ }^{13}$ ), the final result is evidently the same, as shown by Thompson ${ }^{67}$ in a simple case.

\section{Computational Details}

3.1. DFT Calculations. All quantum mechanical DFT calculations have been performed using the Amsterdam density functional (ADF, version 2000) package.$^{54}$ The parametrization of Vosko, Wilk, and Nusair (VWN) ${ }^{68}$ was used for the local density approximation term, and the corrections of Becke (1988) (B) ${ }^{69}$ and Perdew (1986) $(\mathrm{P})^{70}$ were used for the nonlocal exchange and correlation terms. The molecular orbitals were expanded in an uncontracted triple- $\zeta$ Slater-type orbital basis set, along with a single set of polarization functions, which constitutes basis set IV in the ADF code. The inner core shells of $\mathrm{C}(1 \mathrm{~s}), \mathrm{N}(1 \mathrm{~s})$, and $\mathrm{O}(1 \mathrm{~s})$ were treated by the frozen core approximation. The accuracy parameter (accint) for the numerical integration grid was set to 4.0.

Since the solute geometry varies with the solvent, we need to obtain the optimized geometries of the solute in different solvents with different polarities. There is a solvation model in the ADF program named COSMO (conductor-like screening model) which allows us to optimize the solute geometry in solution. ${ }^{40-42}$ The COSMO starts from a solvent model with a dielectric constant equal to infinity and then rescales this back to a finite dielectric using a well-known rescaling formula

$$
f(\epsilon)=(\epsilon-1) /(\epsilon+X)
$$

$X$ is a scaling factor. For large $\epsilon$ 's, $X$ becomes much less important, and the COSMO is most accurate for large $\epsilon$ 's in any event. We have applied $X=0.5$ for diazine calculations in solvents with $\epsilon<5.0 .{ }^{34}$ The default value of $X=0.0$ has been used in the geometry optimizations for Brooker's merocyanine in different solvents.

For the emission processes, geometry optimizations are performed on the first excited singlet state $\left(S_{1}\right)$ (actually a mixed state, we will call it $S_{1}^{\prime}$, see below). An electron is promoted from the $\beta$-HOMO to the $\beta$-LUMO during the $S_{1}^{\prime}$ state geometry optimizations. The $S_{1}^{\prime}$ state energy $\left(E_{S_{1}^{\prime}}\right)$ calculated in this way has to be corrected because of spin-contamination. ${ }^{71,72}$ To achieve spin-decontamination, the first excited triplet state ( $\mathrm{T}_{1}$ ) energy, $E_{\mathrm{T}_{1}}$, (by promoting an electron from the $\beta$-HOMO to the $\alpha$-LUMO) on the same geometry has to be obtained. Then, the $S_{1}$ state energy after spin-decontamination will be $\mathrm{e}^{45,71,72}$

$$
E_{\mathrm{S}_{1}}=2 E_{\mathrm{S}_{1}^{\prime}}-E_{\mathrm{T}_{1}}
$$

The next step is to perform SCRF(FDPB) calculations on the optimized $\left(S_{0}\right.$ or $S_{1}^{\prime}$ state) geometries, to obtain the reaction field potential for the VSCRF calculations. Both the SCRF(FDPB) and VSCRF methods were implemented in the ADF2000 code. The SCRF(FDPB) procedure is described briefly as follows: (1) One performs a gas-phase single-point energy calculation on the COSMO optimized $\left(\mathrm{S}_{0}\right.$ or $\mathrm{S}_{1}^{\prime}$ state) solute structure. (2) The CHELPG program ${ }^{55}$ is then used to fit the point charges of each atom from the molecular electrostatic potentials (ESPs) calculated by the ADF program. (3) One performs the solvation calculation by using the MEAD (Macroscopic Electrostatics with Atomic Detail) program developed by Bashford, ${ }^{73-76}$ to solve the Poisson-Boltzmann equation with a numerical finite-difference method. (4) One adds the reaction field potential obtained from step 3 to the Hamiltonian of the ADF single-point energy calculation. The iteration of steps 1-4 continues until self-consistency between the reaction field potential and the electronic structure of the solute is achieved.

For the emission process, we also perform the first excited triplet state $\left(\mathrm{T}_{1}\right) \mathrm{SCRF}(\mathrm{FDPB})$ calculation (promoting an electron from the $\beta$-HOMO to the $\alpha$-LUMO) at the $\mathrm{S}_{1}^{\prime}$ state COSMO optimized geometry, to obtain the $\mathrm{S}_{1}$ state spindecontamination energy using eq 16.

In COSMO, charge fit, and MEAD calculations, the van der Waals radii for atoms $\mathrm{C}, \mathrm{O}, \mathrm{N}$, and $\mathrm{H}$ were taken as $1.67,1.4$, 1.55, and 1.2 $\AA$, respectively. The dielectric constants of the solvents in COSMO and MEAD (in SCRF) calculations are $\epsilon$ $=1$ for the solute cavity, $\epsilon_{\mathrm{eq}}=1.9$ for $n$-heptane $\left(\mathrm{CH}_{3}\left(\mathrm{CH}_{2}\right)_{5^{-}}\right.$ $\left.\mathrm{CH}_{3}\right), \epsilon_{\mathrm{eq}}=4.6$ for ethyl ether $\left(\mathrm{CH}_{3} \mathrm{CH}_{2} \mathrm{OCH}_{2} \mathrm{CH}_{3}\right), \epsilon_{\mathrm{eq}}=4.7$ for chloroform $\left(\mathrm{CHCl}_{3}\right), \epsilon_{\mathrm{eq}}=8.9$ for dichloromethane $\left(\mathrm{CH}_{2}-\right.$ $\left.\mathrm{Cl}_{2}\right), \epsilon_{\mathrm{eq}}=20.7$ for acetone $\left(\mathrm{C}\left(\mathrm{CH}_{3}\right)_{2} \mathrm{O}\right), \epsilon_{\mathrm{eq}}=37.5$ for acetonitrile $\left(\mathrm{CH}_{3} \mathrm{CN}\right), \epsilon_{\mathrm{eq}}=32.7$ for methanol $\left(\mathrm{CH}_{3} \mathrm{OH}\right)$, and $\epsilon_{\mathrm{eq}}=80$ for $\mathrm{H}_{2} \mathrm{O} . \epsilon_{\mathrm{op}}=2.0$ (except for 1.9 for $n$-heptane) is applied for the solvent region during the VSCRF calculations. The dielectric boundary between the interior (with $\epsilon=1$ ) and the exterior (with $\epsilon=\epsilon_{\mathrm{eq}}$ or $\epsilon_{\mathrm{op}}$ ) of the solute region is defined by the contact surface of rolling a probe sphere (with radius $r$ $=5.6,4.6,3.3,3.3,3.4,3.2,2.5$, and $1.4 \AA$ for the above solvents, respectively) over the solute in both COSMO and MEAD calculations.

In the end of the SCRF(FDPB) iteration, the electronic density distribution, the potential resulting from the reaction field, and the ESP charges at the nuclei are then saved for the VSCRF calculation. The iteration procedure in the VSCRF calculation can be described in the following: (1) For an absorption process, both the $S_{1}^{\prime}$ state and $T_{1}$ state single-point energy calculations are performed at the $\mathrm{S}_{0}$ state COSMO optimized geometry. The reaction field potential $\left(\phi_{\mathrm{i}}^{\mathrm{r}}=\phi_{\mathrm{i}, \mathrm{eq}}^{(\mathrm{r})}\right)$ of the solvated relaxed ground state (obtained from converged SCRF(FDPB) calculations) is added to the Hamiltonian of the two calculations. For the emission process, two $\mathrm{S}_{0}$ state single-point energy calculations are performed at the $S_{1}^{\prime}$ state COSMO optimized geometry, and the reaction field potentials obtained from the $S_{1}^{\prime}$ state and $\mathrm{T}_{1}$ state $\mathrm{SCRF}(\mathrm{FDPB})$ calculations are added separately to the $S_{0}$ state calculations. (2) The electronic density distribution is taken from step 1, and the ESP charges are fitted. (3) The differences of electronic densities ( $\Delta \rho_{\text {if }}$ 's) between the current excited state (for absorption) or ground state (for emission) and the relaxed ground state (for absorption) or excited state (for emission) over the grids of the ADF program are computed. (4) A set of the ESP charge differences for each atom center between the current state and the relaxed state is also calculated. Using this set of ESP difference charges (again with $\epsilon=1$ in the solute region), we then perform a MEAD calculation to get the reaction field potential, $\Delta \phi_{\mathrm{if}}^{\mathrm{r}}=\Delta \phi_{\mathrm{op}}^{\mathrm{r})}$, corresponding to the electronic relaxation of the solvent $\left(\epsilon_{\mathrm{op}}=2\right.$ in the solvent 
TABLE 1: VSCRF and TDDFT Calculated and Experimentally Observed Absorption Energies ( $\left.E_{\text {abs}}\right)$ (electronvolts) for Diazines in Different Solvents ${ }^{a}$

\begin{tabular}{|c|c|c|c|c|c|c|c|c|c|}
\hline \multirow[b]{2}{*}{ solvent } & \multicolumn{3}{|c|}{ pyridazine } & \multicolumn{3}{|c|}{ pyrimidine } & \multicolumn{3}{|c|}{ pyrazine } \\
\hline & VSCRF & TDDFT & exptl & VSCRF & TDDFT & exptl & VSCRF & TDDFT & exptl \\
\hline vacuo & 3.24 & 3.59 & & 3.79 & 4.38 & & 3.43 & 4.00 & \\
\hline$n$-heptane & 3.32 & 3.69 & 3.69 & 3.84 & 4.43 & 4.24 & 3.46 & 4.01 & 3.92 \\
\hline ethyl ether & $3.46(0.14)$ & $3.80(0.11)$ & $3.74(0.05)$ & $3.93(0.09)$ & $4.49(0.06)$ & $4.27(0.03)$ & $3.49(0.03)$ & $4.03(0.02)$ & $3.92(0)$ \\
\hline acetonitrile & $3.57(0.25)$ & $3.90(0.21)$ & $3.85(0.16)$ & $3.99(0.15)$ & $4.55(0.12)$ & $4.32(0.08)$ & $3.52(0.06)$ & $4.06(0.05)$ & $3.94(0.02)$ \\
\hline water (no H-bonds) & $3.63(0.31)$ & $3.91(0.22)$ & & $4.02(0.18)$ & $4.56(0.13)$ & & $3.53(0.07)$ & $4.06(0.05)$ & \\
\hline water $+2 \mathrm{H}_{2} \mathrm{O}^{b}$ & $3.79(0.47)$ & $4.04(0.35)$ & $4.16(0.47)$ & $4.15(0.31)$ & $4.66(0.23)$ & $4.57(0.33)$ & $3.62(0.16)$ & $4.17(0.16)$ & $4.11(0.19)$ \\
\hline
\end{tabular}

${ }^{a}$ The TDDFT data are taken from ref 34. The TDDFT results in water are taken from their "cluster 2" calculations. The experimental values (exptl) are from ref 77. The shifts from $n$-heptane are given in parentheses. ${ }^{b}$ The structures of pyridazine $+2 \mathrm{H}_{2} \mathrm{O}$, pyrimidine $+2 \mathrm{H}_{2} \mathrm{O}$, and pyrazine $+2 \mathrm{H}_{2} \mathrm{O}$ are in Figure $1 \mathrm{a}-\mathrm{c}$, respectively.

region). Then, the vertical excitation and emission energies are computed from eq 12. (5) $\phi_{\mathrm{i}}^{(\mathrm{r})}+\Delta \phi_{\mathrm{if}}^{\mathrm{r}}$ is then added back to the Hamiltonian of the ADF calculation in step 1. The iteration of steps $1-5$ will be repeated until self-consistency between the electron relaxation in the solute and in the solvent is achieved. The final potential is

$$
\phi_{\mathrm{f}}^{\mathrm{r}}=\phi_{\mathrm{i}}^{\mathrm{r}}+\Delta \phi_{\mathrm{if}}^{\mathrm{r}}=\phi_{\mathrm{i}, \mathrm{eq}}^{(\mathrm{r})}+\Delta \phi_{\mathrm{op}}^{(\mathrm{r})}
$$

According to eq 16 , the final $\mathrm{S}_{1}$ state vertical excitation energy or absorption energy can be written as

$$
E_{\mathrm{abs}}=2 \Delta G_{\mathrm{ex}\left(\mathrm{S}_{1}^{\prime}\right)}^{\mathrm{if}}-\Delta G_{\mathrm{ex}\left(\mathrm{T}_{1}\right)}^{\mathrm{if}}
$$

Similarly, the vertical emission energy (absolute value) after spin-decontamination will be

$$
E_{\mathrm{em}}=-\left[2 \Delta G_{\mathrm{em}\left(\mathrm{S}_{1}^{\prime}\right)}^{\mathrm{if}}-\Delta G_{\mathrm{em}\left(\mathrm{T}_{1}\right)}^{\mathrm{if}}\right]
$$

It has been found that the $\triangle \mathrm{SCF}$ procedure of the DFT method underestimates the absolute value of the vertical $S_{1}$ state excitation energy. ${ }^{45}$ However, we will focus more on the relative excitation energies to predict solvent dependencies.

\section{Applications}

4.1. Solvatochromic Shifts of Diazines. The blue shift of the lowest $n \rightarrow \pi^{*}$ electronic transition of diazines and the effects of possible H-bonding interactions between diazine nitrogen atoms and the protic solvent (especially water) hydrogen atoms have been of great interest for many researchers. ${ }^{15-17 a, 26,31,34,77}$ The recent TDDFT study including both the bulk solvent effect and explicit H-bonding interactions predicted very good excitation energies and the blue shifts of the three diazines from vacuo (the experimental data were actually taken in isooctane) to water solution. ${ }^{31}$ Cossi and Barone performed similar TDDFT calculations on the diazines in more solvents, including $n$-heptane, ethyl ether, acetonitrile, and water. ${ }^{34}$ The three diazines are also known as pyridazine (1,2-diazine), pyrimidine (1,3-diazine), and pyrazine (1,4-diazine). ${ }^{31}$ Before applying the VSCRF method to larger systems, we first would like to see how our method compares with the TDDFT ${ }^{34}$ and the experimental data ${ }^{77}$ for the blue shifts of diazines with increasing solvent polarities from $n$-heptane to water solutions. We will also see if the explicit $\mathrm{H}$-bonding $\mathrm{H}_{2} \mathrm{O}$ effect is important to include in our model calculations in order to predict accurate shifts.

Our VSCRF results together with the TDDFT and experimental data are given in Table 1. Two cases are considered for the solutes in $\mathrm{H}_{2} \mathrm{O}$. One is without $\mathrm{H}$-bonding interactions; the other is with two explicit $\mathrm{H}$-bonding $\mathrm{H}_{2} \mathrm{O}$ molecules. All geometries in $\mathrm{H}_{2} \mathrm{O}$ are optimized using the COSMO in the ADF

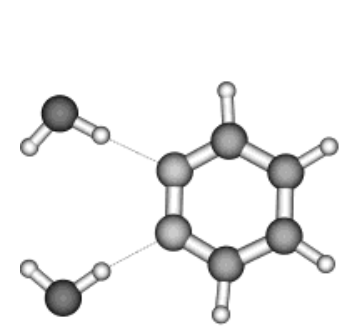

(a)
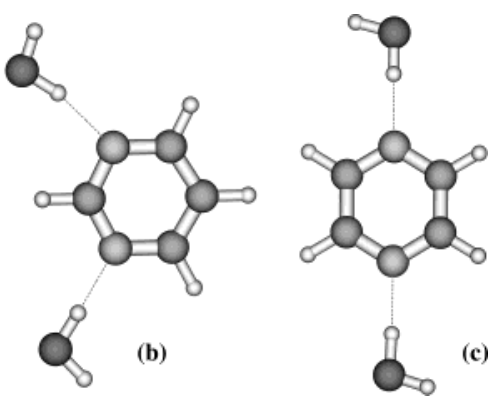

Figure 1. COSMO optimized structures of diazines with two explicit H-bonding $\mathrm{H}_{2} \mathrm{O}$ molecules in water solution: (a) pyridazine $+2 \mathrm{H}_{2} \mathrm{O}$; (b) pyrimidine $+2 \mathrm{H}_{2} \mathrm{O}$; (c) pyrazine $+2 \mathrm{H}_{2} \mathrm{O}$.

program. Then, the $S_{0}$ state $S C R F(F D P B)$ and the $S_{1}^{\prime}$ state and $\mathrm{T}_{1}$ state VSCRF calculations are performed upon the COSMO optimized geometries. The structures of the diazines with two $\mathrm{H}_{2} \mathrm{O}$ molecules are shown in Figure 1.

We see the TDDFT method is obviously better than the $\triangle \mathrm{SCF}$ calculations in predicting the absolute values of the vertical excitation energies. As expected, the $\triangle \mathrm{SCF}$ method underestimates the $S_{1}$ state excitation energies. However, the SCRF/ VSCRF(FDPB) calculations are as good as the TDDFT in predicting the blue shift energies of the diazines from $n$-heptane to water solutions. In the low dielectric region, our VSCRF method predicts a little larger energy shift (from $n$-heptane to ethyl ether or acetonitrile) than the corresponding TDDFT results. However, the blue shifts from $n$-heptane to water obtained by VSCRF calculations are much closer to those from the experimental data than those from the TDDFT results, especially for pyridazine and pyrimidine.

If no explicit $\mathrm{H}$-bonding $\mathrm{H}_{2} \mathrm{O}$ molecules are considered, the VSCRF calculations also underestimate the blue shifts (or the vertical excitation energy differences of $\Delta E_{\mathrm{abs}}=E_{\mathrm{abs}}\left(\mathrm{H}_{2} \mathrm{O}\right)-$ $E_{\text {abs }}(n$-heptane $\left.)\right)$ for the three molecules. Compared with the corresponding TDDFT values of $\Delta E_{\mathrm{abs}}$, the VSCRF results are on average $0.05 \mathrm{eV}$ closer to the experimental data. When two explicit $\mathrm{H}$-bonding $\mathrm{H}_{2} \mathrm{O}$ molecules are included in the model (see Figure 1), the VSCRF calculations predict $\Delta E_{\mathrm{abs}}$ values of $0.47 \mathrm{eV}$ for pyridazine, which reproduces the experimental shift value, and $0.31 \mathrm{eV}$ for pyrimidine, which is also in very good agreement with the observed shift of $0.33 \mathrm{eV}$ and still better than the corresponding TDDFT result of $0.23 \mathrm{eV}$.

Here, the VSCRF calculations also show that consideration of the H-bonding effects is very important in order to predict the correct blue shifts for diazines from $n$-heptane to water. Now we apply the VSCRF calculations to Brooker's merocyanine for both absorption and emission processes.

4.2. Applications to Brooker's Merocyanine. Brooker's merocyanine is a typical solvent-sensitive dye which was proposed as an indicator of solvent polarity. ${ }^{1}$ 

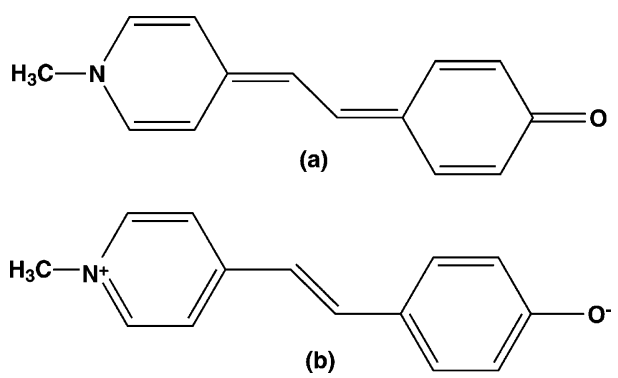

Figure 2. (a) Quinonoid structure of Brooker's merocyanine. (b) Benzenoid (zwitterion) structure.

It has been found that the excitation energy of this dye changes dramatically by $0.78-0.80 \mathrm{eV}$ from $\mathrm{CHCl}_{3}$ to $\mathrm{H}_{2} \mathrm{O}$ solution. ${ }^{22,24,64,65}$ There is also a blue shift of the fluorescence bands with increasing solvent polarity, which was reported very recently by Baraldi et al. ${ }^{24}$ In this paper, we will compare our results with the experimental data presented in Baraldi's paper.

It has been suggested that the large solvatochromic shift is caused by a distinct change of this molecule from a quinonoid structure (Figure 2a) in nonpolar solvents, such as chloroform, to a benzenoid (zwitterion) structure (Figure 2b) in polar solvents, such as water. Several semiempirical calculations using AM1, PM3, CNDO, INDO, and Hartree-Fock calculations all predicted a quinone structure for this molecule in the gas phase. The semiempirical methods plus reaction field calculations also predicted that the quinone structure is dominant at low dielectric constants. ${ }^{11,12,20-22,24,61-63}$ However, experimental evidence from NMR spectroscopy demonstrates that Brooker's merocyanine is mainly in the zwitterionic structure even in solvents of low dielectric constants, such as chloroform. ${ }^{22}$ None of the theoretical calculations so far have correctly reproduced the experimental structure of this molecule in nonpolar solutions. ${ }^{22}$ The DFT with BLYP potential calculations performed by Morley et al. obtained the gas-phase structure with nearly equal bond lengths of 1.409 , 1.417, and $1.411 \AA$ for the three central $\mathrm{C}-\mathrm{C}$ bonds. They therefore suggested that the real structure in the gas phase may also be a zwitterion and the conventional molecular orbital methods at the Hartree-Fock level are not able to reproduce the correct geometry. Here, we take this molecule as an example to see if the DFT VWN/BP method plus the COSMO solvation model will reproduce the experimental structure of this molecule in $\mathrm{CHCl}_{3}$; how the solute-solvent interactions will influence the molecular structures, charge distributions, and excitation energies; how explicit H-bonding interactions with two to four water molecules will influence the excitation energy of this dye in water solution; and, furthermore, if the VSCRF calculations will predict correct shift trends of the absorption and emission bands of this molecule in other solvents with increasing solvent polarities.

4.2.1. SCRF/VSCRF(FDPB) Calculations at the Gas-Phase Geometry. The optimized gas-phase geometry of Brooker's merocyanine is shown in Figure 3a. Just as Morley et al. found, the three middle $\mathrm{C}-\mathrm{C}$ bonds are of nearly equal bond lengths of $1.400,1.403$, and $1.401 \AA$. The central $\mathrm{C}_{2}-\mathrm{C}_{3}$ bond is very slightly longer than the $\mathrm{C}_{1}-\mathrm{C}_{2}$ and $\mathrm{C}_{3}-\mathrm{C}_{4}$ bonds. It is expected that upon solvation, even with fairly nonpolar solvents, the molecular structure will change. Normally, the solute structure will be the combination of the two extreme resonance quinoidal and zwitterionic structures, and the contribution of the two extreme resonance forms to the resonance hybrid varies in different solvents. ${ }^{78}$

The importance of geometry optimizing solute structure in solvents with different polarities has been addressed. ${ }^{20}$ Now

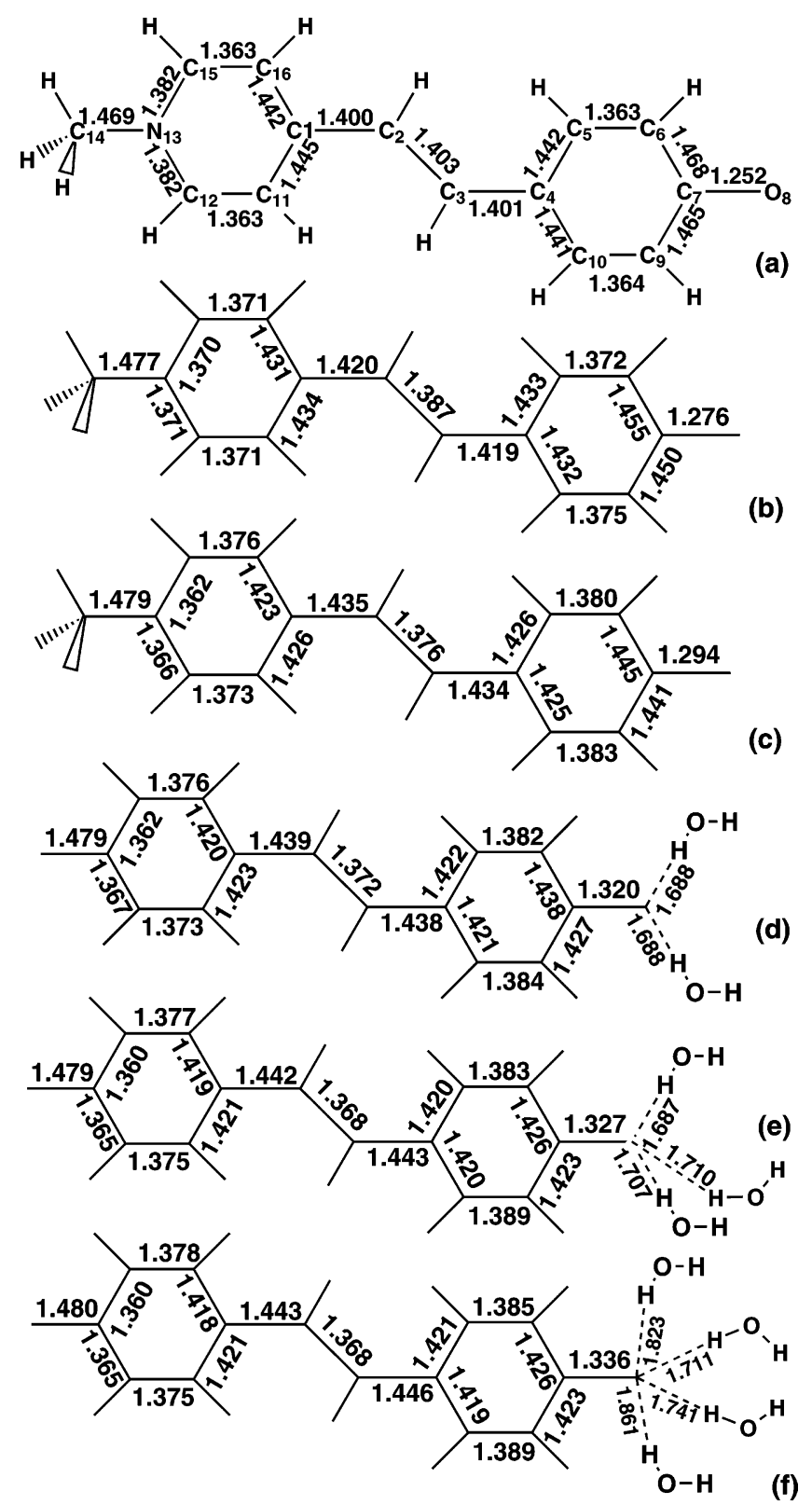

Figure 3. Main bond lengths of the ground state Brooker's merocyanine (a) in the gas phase, (b) in $\mathrm{CHCl}_{3}$, (c) in $\mathrm{H}_{2} \mathrm{O}$ without explicit $\mathrm{H}_{2} \mathrm{O}$ molecules, (d) in $\mathrm{H}_{2} \mathrm{O}$ with two $\mathrm{H}$-bonding $\mathrm{H}_{2} \mathrm{O}$ molecules, (e) in $\mathrm{H}_{2} \mathrm{O}$ with three $\mathrm{H}$-bonding $\mathrm{H}_{2} \mathrm{O}$ molecules, and (f) in $\mathrm{H}_{2} \mathrm{O}$ with four H-bonding $\mathrm{H}_{2} \mathrm{O}$ molecules.

assuming initially that the molecular geometry does not change upon solvation, we would like to see if the SCRF(FDPB) and VSCRF calculations will predict the solvatochromic shift from $\mathrm{CHCl}_{3}$ to $\mathrm{H}_{2} \mathrm{O}$, and then how important the geometry relaxation will be in improving the calculations. Therefore, the SCRF(FDPB) and VSCRF calculations were first performed upon the gas-phase structure of this molecule.

The values of dipole moment $(\mu)$ and the energy terms in eqs 8 and 12 are given in Table 2.

Upon solvation, the electronic structure is rearranged and the solute electronic energy $\left(E_{0}^{\mathrm{i}}\right)$ increases with increasing solvent polarity (see Table 2). However, the reaction field energy $\left(W_{\mathrm{i}}^{\mathrm{r}}\right)$ decreases more significantly, and therefore, the total free energy $\left(G_{0}^{\mathrm{i}}\right)$ of the system decreases with increasing solvent polarity.

In the ground state, the highest occupied molecular orbital (HOMO) is mainly localized on atoms $\mathrm{C}_{2}, \mathrm{C}_{4}, \mathrm{O}_{8}, \mathrm{C}_{6}, \mathrm{C}_{9}, \mathrm{~N}_{13}$, $\mathrm{C}_{16}$, and $\mathrm{C}_{11}$ (see the molecular orbital plot of the solute in 
TABLE 2: Ground $\left(S_{0}\right)$ and Vertical First Excited Singlet State $\left(S_{1}\right)$ Dipole Moment Values $\left(\mu_{S_{0}}\right.$ and $\left.\mu_{S_{1}^{\prime}}^{v}\right)($ debyes$)$, $S_{0}$ State Energies $\left(G_{0}^{\mathrm{i}}=E_{0}^{\mathrm{i}}+W_{\mathrm{i}}^{\mathrm{r}}\right)$ (electronvolts), and Vertical Excitation Energies $\left(\boldsymbol{E}_{\mathrm{abs}}=\boldsymbol{\Delta} \boldsymbol{E}_{\mathbf{0}}+\boldsymbol{\Delta} \boldsymbol{G}_{\mathrm{pot}}+\boldsymbol{\Delta} \boldsymbol{G}_{\text {res}}\right)$ (electronvolts) Calculated at the Gas-Phase Geometry of Brooker's Merocyanine ${ }^{a}$

\begin{tabular}{|c|c|c|c|c|c|c|c|c|c|c|}
\hline \multirow[b]{3}{*}{ solvent } & \multicolumn{4}{|c|}{ relaxed $S_{0}$ state $^{b}$} & \multicolumn{6}{|c|}{ vertical $S_{1}$ state $^{c}$} \\
\hline & \multirow[b]{2}{*}{$\mu_{\mathrm{S}_{0}}$} & \multirow[b]{2}{*}{$E_{0}^{\mathrm{i}}$} & \multirow[b]{2}{*}{$W_{\mathrm{i}}^{\mathrm{r}}$} & \multirow[b]{2}{*}{$G_{0}^{\mathrm{i}}$} & \multirow[b]{2}{*}{$\mu_{\mathrm{S}_{1}^{\prime}}^{\mathrm{v}}$} & \multirow[b]{2}{*}{$\Delta E_{0}$} & \multirow[b]{2}{*}{$\Delta G_{\mathrm{pot}}$} & \multirow[b]{2}{*}{$\Delta G_{\text {res }}$} & \multicolumn{2}{|c|}{$E_{\text {abs }}$} \\
\hline & & & & & & & & & VSCRF & $\operatorname{exptl}^{d}$ \\
\hline gas phase & 16.23 & -184.337 & 0.000 & -184.337 & 15.62 & 1.610 & 0.000 & 0.000 & 1.610 & \\
\hline $\mathrm{CHCl}_{3}$ & 25.73 & -183.928 & -1.192 & -185.120 & 23.33 & 1.466 & 0.162 & -0.004 & 1.624 & 2.022 \\
\hline $\mathrm{H}_{2} \mathrm{O}$ & 30.83 & -183.358 & -2.229 & -185.587 & 27.88 & 1.332 & 0.429 & -0.007 & 1.754 & 2.799 \\
\hline
\end{tabular}

${ }^{a}$ The geometry of the gas-phase Brooker's merocyanine is shown in Figure 3a. ${ }^{b}$ See eq 8 for the energy terms. Values in $\mathrm{CHCl}_{3}$ and in $\mathrm{H}_{2} \mathrm{O}$ are obtained after the SCRF(FDPB) calculations. ${ }^{c}$ See eqs 12 and 18 for the energy terms. Values in $\mathrm{CHCl}_{3}$ and in $\mathrm{H}_{2} \mathrm{O}$ are from the VSCRF calculations. Spin-decontamination has been applied to every energy term according to eq $16 .{ }^{d}$ From ref 24.
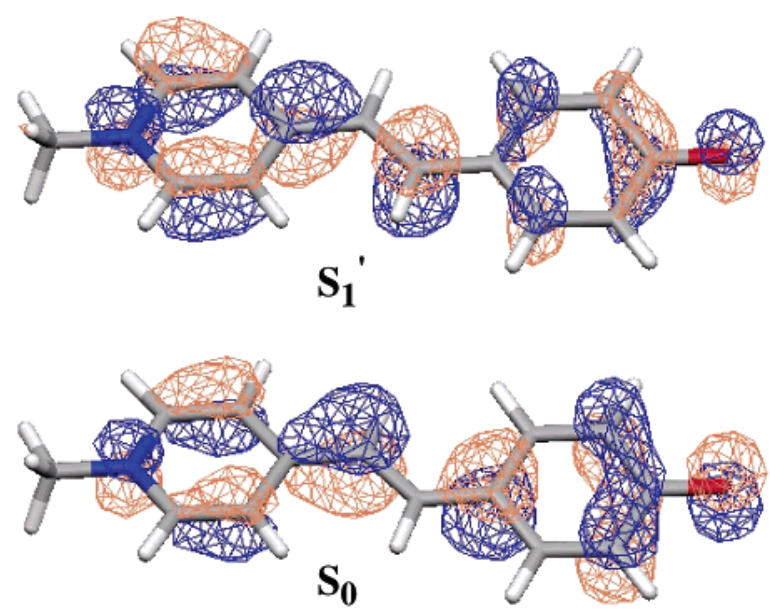

Figure 4. Molecular orbital plots for the electron in the $\alpha$-HOMO of the ground state $\left(\mathrm{S}_{0}\right)$ and the $\pi \rightarrow \pi^{*}$ promoted electron in the vertical $\mathrm{S}_{1}^{\prime}$ state (see text). The electronic structures are obtained for Brooker's merocyanine from the $\mathrm{SCRF}(\mathrm{FDPB})$ calculations in $\mathrm{CHCl}_{3}$ at the gasphase geometry. The figure is generated with MOLEKEL. ${ }^{79}$

$\mathrm{CHCl}_{3}$ as an example in Figure 4, labeled as $\mathrm{S}_{0}$ ). But the energies of molecular orbitals, the contributions of the atomic orbitals to the molecular orbital, and the bonding characters of the central $\mathrm{C}-\mathrm{C}$ bonds vary upon solvation. From the gas phase to nonpolar $\left(\mathrm{CHCl}_{3}\right)$ and polar $\left(\mathrm{H}_{2} \mathrm{O}\right)$ solutions, the distribution of the $\pi$ electrons moves toward the right side of the molecule. In the gas phase, the dipole moment of this molecule is only $16.23 \mathrm{D}$. In contrast, in solution, the right side becomes more negative and the left more positive. The dipole moment increases to 25.73 and $30.83 \mathrm{D}$ in $\mathrm{CHCl}_{3}$ and in $\mathrm{H}_{2} \mathrm{O}$, respectively. Comparing the ground state energies $\left(G_{0}^{\mathrm{i}}\right)$, we found that the solvation effect in $\mathrm{CHCl}_{3}$ stabilizes the molecule by $0.78 \mathrm{eV}$, while, in $\mathrm{H}_{2} \mathrm{O}$ solution, the energy goes down further by $0.47 \mathrm{eV}$.

As an example, the molecular orbital plot for the $\pi \rightarrow \pi^{*}$ promoted electron of the vertical $\mathrm{S}_{1}^{\prime}$ state in $\mathrm{CHCl}_{3}$ is also given in Figure 4 . The $\pi$ orbitals of atoms $C_{1}$ and $C_{3}$ have the largest contribution to this molecular orbital. This contrasts with the ground state, where this electron is mostly localized at atoms $\mathrm{C}_{2}$ and $\mathrm{C}_{4}$. Therefore, from the $\mathrm{S}_{0}$ state to the $\mathrm{S}_{1}^{\prime}$ state, the electron density shifts to the left side of the molecule. We see the dipole moments in the $S_{1}^{\prime}$ state of the molecule are all smaller than the corresponding ones in the $S_{0}$ state. This is consistent with what is normally observed from experiments, since, if the dipole moment of the solute decreases during the electronic transition, the Franck-Condon excited state is in a strained solvent cage of oriented dipoles not correctly disposed to efficiently stabilize the excited state. Thus, with increasing solvent polarity, the energy of the ground state is lowered more than that of the excited state, and this produces a blue shift. ${ }^{1}$
For comparison, we also obtained the components of the vertical excited state dipole moment by using twice the $S_{1}^{\prime}$ state value minus the corresponding $\mathrm{T}_{1}$ state dipole moment component. The vertical state dipole moments obtained using this averaging process are 23.52 and $27.09 \mathrm{D}$ in $\mathrm{CHCl}_{3}$ and $\mathrm{H}_{2} \mathrm{O}$, respectively, which are very close to the $\mu_{\mathrm{S}_{1}^{\prime}}^{\mathrm{v}}$ values of 23.33 and $27.88 \mathrm{D}$, respectively.

In Table 2, we see that the vertical excitation energy $\left(E_{\mathrm{abs}}\right)$ mainly comes from the change in the solute electronic energy $\left(\Delta E_{0}\right)$. The response term (caused by the electron relaxation in the solvent) $\left(\Delta G_{\text {res }}\right)$ is very small. The potential term (caused by the reorganization of the solute electronic structure within the reaction field) $\left(\Delta G_{\mathrm{pot}}\right)$, although much smaller than $\Delta E_{0}$, is important to determine the total $E_{\text {abs }}$ value. For this system, $\Delta E_{0}$ decreases but $\Delta G_{\text {pot }}$ increases, and overall, $E_{\text {abs }}$ increases with increasing solvent polarity. (This opposite shift of $\Delta E_{0}$ compared to $\Delta G_{\mathrm{pot}}$, with $\Delta G_{\mathrm{pot}}$ being larger, is expected for a linear response dielectric medium. $\Delta E_{0}$ (solvent) $-\Delta E_{0}$ (gas) is the "electronic strain term" in the excitation energy (see refs 55, 57, and 66). However, the vertical excited state is a "nonequilibrium" state with respect to both geometry and solvation.) Here, we correctly predicted the blue shift when going from the solvent $\mathrm{CHCl}_{3}$ to $\mathrm{H}_{2} \mathrm{O}$. However, the relative shift of $E_{\mathrm{abs}}-$ $\left(\mathrm{CHCl}_{3}\right)$ versus $E_{\text {abs }}\left(\mathrm{H}_{2} \mathrm{O}\right)(0.130 \mathrm{eV})$ is much smaller than the observed value of $0.777 \mathrm{eV}$.

4.2.2. SCRF/VSCRF(FDPB) Calculations at the COSMO Optimized Geometries. To see if geometric relaxation in solution will improve the predicted solvatochromic properties, and how the molecular structure will change upon solvation, we geometry optimized the structure using the COSMO solvation model in the ADF program. The main bond lengths of the optimized structures are shown in Figure $3 \mathrm{~b}$ (in $\mathrm{CHCl}_{3}$ ) and c (in $\mathrm{H}_{2} \mathrm{O}$ ). The SCRF(FDPB) and VSCRF calculations were then performed at the optimized geometries. The values of dipole moment $(\mu)$ and the ground state and vertical excitation energy terms in eqs 8 and 12 (after spin-decontamination) for the dye in the $\mathrm{CHCl}_{3}$ and $\mathrm{H}_{2} \mathrm{O}$ solutions are given in Table 3 .

Compared with the energy terms obtained from the SCRF(FDPB) calculations at the gas-phase geometry (Table 2), after the geometry relaxation in $\mathrm{CHCl}_{3}$ and $\mathrm{H}_{2} \mathrm{O}$, the electronic energy ( $E_{0}^{\mathrm{i}}$, associated with the zeroth order "gas-phase" Hamiltonian) of the solute is further increased and the reaction field energy $\left(W_{\mathrm{i}}^{\mathrm{r}}\right)$ stabilized with increasing solvent polarity. The total energy $\left(G_{0}^{\mathrm{i}}\right)$ of the molecule in $\mathrm{CHCl}_{3}$ (after the SCRF calculations) is slightly stabilized by $0.050 \mathrm{eV}$; however, the $G_{0}^{\mathrm{i}}$ in $\mathrm{H}_{2} \mathrm{O}$ is lowered significantly by $0.145 \mathrm{eV}$. In the excitation process, now the values of $\Delta E_{0}$ are smaller, but the reaction field effects are much larger than the corresponding ones obtained at the gas-phase geometry. $\mathrm{In}_{2} \mathrm{O}$ solution (Table $3)$, the $\Delta G_{\text {pot }}$ and the $\Delta E_{0}$ terms have nearly equal contributions 
TABLE 3: Dipole Moments $\left(\boldsymbol{\mu}_{\mathrm{S}_{0}}\right.$ and $\left.\boldsymbol{\mu}_{\mathrm{S}_{1}^{\prime}}^{\mathrm{v}}\right)$ (debyes), $\mathbf{S}_{\mathbf{0}}$ State Energies $\left(G_{0}^{\mathrm{i}}\right)$ (electronvolts), and Vertical Excitation Energies $\left(\boldsymbol{E}_{\mathrm{abs}}\right)$ (electronvolts) Calculated at the COSMO Optimized Geometries of Brooker's Merocyanine

\begin{tabular}{|c|c|c|c|c|c|c|c|c|c|c|c|c|}
\hline \multirow[b]{3}{*}{ solvent } & \multicolumn{6}{|c|}{ relaxed $S_{0}$ state } & \multicolumn{6}{|c|}{ vertical $S_{1}$ state $^{c}$} \\
\hline & \multicolumn{2}{|c|}{$\operatorname{cosMO}^{a}$} & \multicolumn{4}{|c|}{ SCRF(FDPB $)^{b}$} & \multirow[b]{2}{*}{$\mu_{\mathrm{S}_{1}^{\prime}}^{\mathrm{v}}$} & \multirow[b]{2}{*}{$\Delta E_{0}$} & \multirow[b]{2}{*}{$\Delta G_{\mathrm{pot}}$} & \multirow[b]{2}{*}{$\Delta G_{\text {res }}$} & \multicolumn{2}{|c|}{$E_{\text {abs }}$} \\
\hline & $\mu_{\mathrm{S}_{0}}$ & $G_{0}^{\mathrm{i}}$ & $\mu_{\mathrm{S}_{0}}$ & $E_{0}^{\mathrm{i}}$ & $W_{\mathrm{i}}^{\mathrm{r}}$ & $G_{0}^{\mathrm{i}}$ & & & & & VSCRF & exptl \\
\hline $\mathrm{CHCl}_{3}$ & 27.80 & -185.167 & 27.97 & -183.800 & -1.370 & -185.170 & 23.78 & 1.287 & 0.350 & -0.009 & 1.628 & 2.022 \\
\hline $\mathrm{H}_{2} \mathrm{O}$ & 34.84 & -185.599 & 35.84 & -182.844 & -2.888 & -185.732 & 30.33 & 1.082 & 0.902 & -0.018 & 1.966 & 2.799 \\
\hline
\end{tabular}

${ }^{a}$ Results obtained from the ADF output after geometry optimization using COSMO. ${ }^{b}$ Results obtained from converged SCRF(FDPB) calculations at the COSMO optimized geometries. See eq 8 for the energy terms. $G_{0}^{\mathrm{i}}=E_{0}^{\mathrm{i}}+W_{\mathrm{i}}^{\mathrm{r}}{ }^{c}$ See eqs 12 and $18 . E_{\mathrm{abs}}=\Delta E_{0}+\Delta G_{\mathrm{pot}}+\Delta G_{\text {res. }}$ Spindecontamination has been applied to every energy term according to eq 16.

to the vertical excitation energy $\left(E_{\mathrm{abs}}\right)$. Also, $\Delta G_{\mathrm{pot}}$ still is larger than the electronic strain term in the excitation energy, which has opposite sign. Again, the blue shift in $E_{\text {abs }}$ follows that in $\Delta G_{\text {pot}}$.

After geometry relaxation in solution, the $E_{\text {abs }}$ value in $\mathrm{CHCl}_{3}$ is only increased by $0.004 \mathrm{eV}$ but the one in $\mathrm{H}_{2} \mathrm{O}$ solution is increased by $0.212 \mathrm{eV}$. The energy difference between the two bands now is changed to $0.34 \mathrm{eV}$, which is closer to the experimental value of $0.78 \mathrm{eV}$. Therefore, for predicting reasonable vertical excitation energies from the VSCRF calculations, geometry relaxation is very important, especially for the structures in polar solutions, such as $\mathrm{H}_{2} \mathrm{O}$.

Comparing with the gas-phase geometry, we found that the central $\mathrm{C}_{2}-\mathrm{C}_{3}$ bond in the COSMO optimized structure in $\mathrm{CHCl}_{3}$ now is shortened by $0.016 \AA$ and the distances of $\mathrm{C}_{1}-$ $\mathrm{C}_{2}$ and $\mathrm{C}_{3}-\mathrm{C}_{4}$ are elongated by about $0.02 \AA$. We see the structure changed toward the zwitterion form. This is consistent with the ${ }^{1} \mathrm{H}$ and ${ }^{13} \mathrm{C}$ NMR experimental results which suggest that Brooker's merocyanine exists as a resonance hybrid which is weighted toward the zwitterion even in the nonpolar solvent, $\mathrm{CHCl}_{3}{ }^{22}$ All previous semiempirical calculations were not able to predict this zwitterion structure in $\mathrm{CHCl}_{3} .{ }^{11,12,20-22,61-63}$ Here again, we see the merit of the DFT method in structural property calculations. When going to the $\mathrm{H}_{2} \mathrm{O}$ solution, the structure is even more polarized with distinct single-double-single bond character for these three bonds. Now $\mathrm{C}_{2}-\mathrm{C}_{3}$ is shortened by $0.027 \AA$ and $\mathrm{C}_{1}-\mathrm{C}_{2}$ and $\mathrm{C}_{3}-\mathrm{C}_{4}$ are elongated by more than $0.03 \AA$. The $\mathrm{C}_{7}-\mathrm{O}_{8}$ bond is significantly elongated from 1.252 $\AA$ in the gas phase to $1.294 \AA$ in $\mathrm{H}_{2} \mathrm{O}$. After geometry relaxation, the calculated dipole moment is enlarged by 2.24 and $5.01 \mathrm{D}$ in $\mathrm{CHCl}_{3}$ and $\mathrm{H}_{2} \mathrm{O}$ solutions, respectively.

To see how the SCRF(FDPB) procedure will reproduce the electronic structure at the COSMO optimized geometries, we give in Table 3 the ground state dipole moment $\left(\mu_{\mathrm{S}_{0}}\right)$ and the total energy values $\left(G_{0}^{\mathrm{i}}\right)$ obtained from both the ADF output after the COSMO geometry optimization and the result from the converged SCRF(FDPB) calculation. The two methods predict nearly the same values of $\mu_{\mathrm{S}_{0}}$ and $G_{0}^{\mathrm{i}}$ for the structure in $\mathrm{CHCl}_{3}$ solution. In water solution, the results from the SCRF(FDPB) procedure are different from those of the ADF(COSMO) calculation by only $1.00 \mathrm{D}$ for the dipole moment and $0.133 \mathrm{eV}$ for the total energy. With the same set of atomic radii, solvent radius, and dielectric constant, the continuum solvent models of the COSMO and the SCRF(FDPB) calculations will predict quite similar electronic structures and energies for this dye molecule.

4.2.3. Improvement by Adding Explicit H-Bonding Water Molecules. Though the absolute and relative vertical excitation energies predicted by the SCRF/VSCRF(FDPB) calculations are improved by using the COSMO optimized geometries, the energy difference between $E_{\text {abs }}\left(\mathrm{CHCl}_{3}\right)$ and $E_{\mathrm{abs}}\left(\mathrm{H}_{2} \mathrm{O}\right)$ is still much smaller than the experimental value. Morley et al.
TABLE 4: Ground and Vertical $S_{1}$ State Dipole Moment Values $\left(\mu_{\mathrm{S}_{0}}\right.$ and $\left.\mu_{\mathrm{S}_{1}}^{\mathrm{v}}\right)$ (debyes) and Vertical Excitation Energies $\left(E_{\mathrm{abs}}=\Delta E_{0}+\Delta G_{\mathrm{pot}}+\Delta G_{\mathrm{res}}\right)$ (electronvolts) of Brooker's Merocyanine with Two, Three, and Four Explicit H-Bonding $\mathrm{H}_{2} \mathrm{O}$ Molecules Obtained from VSCRF Calculations ${ }^{a}$

\begin{tabular}{ccccccccc}
\hline & & & & & & & \multicolumn{3}{c}{$\begin{array}{l}E_{\text {abs }}\left(\mathrm{H}_{2} \mathrm{O}\right)- \\
\text { model }\end{array}$} & $\mu_{\mathrm{S}_{0}}$ & $\mu_{\mathrm{S}_{1}^{\prime}}^{\mathrm{v}}$ & $\Delta E_{0}$ & $\Delta G_{\text {pot }}$ & $\Delta G_{\text {res }}$ & $E_{\text {abs }}$ & calcd & exptl \\
\hline$+2 \mathrm{H}_{2} \mathrm{O}$ & 37.38 & 31.27 & 1.227 & 0.927 & -0.032 & 2.122 & 0.494 & \\
$+3 \mathrm{H}_{2} \mathrm{O}$ & 37.36 & 30.96 & 1.327 & 0.877 & -0.028 & 2.176 & 0.548 & 0.777 \\
$+4 \mathrm{H}_{2} \mathrm{O}$ & 37.86 & 31.46 & 1.401 & 0.863 & -0.029 & 2.235 & 0.607 &
\end{tabular}

${ }^{a}$ See Figure $5 \mathrm{~d}-\mathrm{f}$. Ground state geometries were optimized using the COSMO. Energy terms are give after spin-decontamination.

observed that the large blue shift in protic solvents arises from both a dielectric effect and a hydrogen bonding effect. ${ }^{22}$ Notice that, for the electronic structure of the molecule in $\mathrm{H}_{2} \mathrm{O}$ solution, the largest contribution $(21.0 \%)$ of the electron in the $\alpha$-HOMO (the same for the $\beta$-HOMO) comes from atom $\mathrm{O}_{8}$ (for other atoms: $\mathrm{C}_{4}(16.9 \%), \mathrm{C}_{2}(16.1 \%), \mathrm{C}_{9}(11.4 \%), \mathrm{C}_{6}(9.2 \%), \mathrm{C}_{7}$ $(5.2 \%), \mathrm{N}_{13}(4.6 \%), \mathrm{C}_{16}(4.0 \%), \mathrm{C}_{11}$ (3.7\%), $\mathrm{C}_{15}(1.0 \%)$ ); certainly the explicit $\mathrm{H}$-bonding water molecules around atom $\mathrm{O}_{8}$ would influence the charge distributions and the $\pi \rightarrow \pi^{*}$ transition energies. Here, we studied three models with two, ${ }^{22}$ three, and four water molecules, respectively, and optimized the structures using the COSMO. The two water molecules in the $+2 \mathrm{H}_{2} \mathrm{O}$ model are in the same plane of the solute, and the $\mathrm{H}$-bonds of the $+3 \mathrm{H}_{2} \mathrm{O}$ model are in a tetrahedral form, like the $\mathrm{C}-\mathrm{H}_{3}$ group. In the $+4 \mathrm{H}_{2} \mathrm{O}$ model, two water molecules are in the same plane of the solute and another two are in the plane perpendicular to the solute. The main bond lengths of the optimized geometries for the $+2 \mathrm{H}_{2} \mathrm{O},+3 \mathrm{H}_{2} \mathrm{O}$, and $+4 \mathrm{H}_{2} \mathrm{O}$ models are shown in Figure $3 \mathrm{~d}-\mathrm{f}$, respectively.

By adding two $\mathrm{H}$-bonding $\mathrm{H}_{2} \mathrm{O}$ molecules, the vertical excitation energy $\left(E_{\mathrm{abs}}=2.122 \mathrm{eV}\right.$, see Table 4$)$ is obtained from the SCRF/VSCRF(FDPB) calculations, which is larger by $0.156 \mathrm{eV}$ than the previous one without considering the $\mathrm{H}$-bonding $\mathrm{H}_{2} \mathrm{O}$ molecules. This increment comes from changing both $\Delta E_{0}$ and $\Delta G_{\text {pot }}$. The energy difference of $E_{\mathrm{abs}}\left(\mathrm{H}_{2} \mathrm{O}\right)-E_{\mathrm{abs}^{-}}$ $\left(\mathrm{CHCl}_{3}\right)$ is increased to $0.494 \mathrm{eV}$, which is again closer to the experimental value of $0.777 \mathrm{eV}$. The structure of the molecule is further polarized with the central $\mathrm{C}_{2}=\mathrm{C}_{3}$ bond shortened and the two single bonds, $\mathrm{C}_{1}-\mathrm{C}_{2}$ and $\mathrm{C}_{3}-\mathrm{C}_{4}$, lengthened by 0.004 $\AA$. The distance of $\mathrm{C}_{7}-\mathrm{O}_{8}$ is elongated by $0.026 \AA$, and the dipole moment, $\mu_{\mathrm{S}_{0}}$ (see Tables 3 and 4 ), is changed from 35.84 to $37.38 \mathrm{D}$. The energy gap between the LUMO and the HOMO is increased from 1.757 to $1.863 \mathrm{eV}$.

Meanwhile, in the $+3 \mathrm{H}_{2} \mathrm{O}$ and $+4 \mathrm{H}_{2} \mathrm{O}$ models, the vertical excitation energy is further increased to 2.176 and $2.235 \mathrm{eV}$, respectively, and the energy difference of $E_{\mathrm{abs}}\left(\mathrm{H}_{2} \mathrm{O}\right)-E_{\mathrm{abs}}-$ $\left(\mathrm{CHCl}_{3}\right)$ is increased to 0.548 and $0.607 \mathrm{eV}$, respectively. Comparing with the $+2 \mathrm{H}_{2} \mathrm{O}$ model, we found that the increased 
TABLE 5: SCRF/VSCRF(FDPB) Calculated and Experimentally Observed Absorption $\left(\boldsymbol{E}_{\text {abs }}\right)$ and Emission $\left(\boldsymbol{E}_{\mathrm{em}}\right)$ Energies (electronvolts) and Relaxed and Vertical Transition $S_{0}$ State and $S_{1}$ State Dipole Moments for Brooker's Merocyanine in Different Solvents

\begin{tabular}{|c|c|c|c|c|c|c|c|c|c|}
\hline \multirow[b]{3}{*}{ solvent } & & \multicolumn{4}{|c|}{ absorption } & \multicolumn{4}{|c|}{ emission } \\
\hline & & \multirow[b]{2}{*}{$\mu_{\mathrm{S}_{0}}$} & \multirow[b]{2}{*}{$\mu_{\mathrm{S}_{1}^{\prime}}^{\mathrm{v}}$} & \multicolumn{2}{|c|}{$E_{\text {abs }}$} & \multirow[b]{2}{*}{$\mu_{\mathrm{S}_{1}^{\prime}}$} & \multirow[b]{2}{*}{$\mu_{\mathrm{S}_{0}}^{\mathrm{v}}$} & \multicolumn{2}{|c|}{$E_{\mathrm{em}}$} \\
\hline & & & & VSCRF & $\operatorname{expt}^{a}$ & & & VSCRF & $\operatorname{exptl}^{a}$ \\
\hline gas phase & & 16.23 & 15.62 & 1.610 & & 15.24 & 17.34 & 1.346 & \\
\hline \multirow[t]{2}{*}{ chloroform } & no H-bonds & 27.97 & 23.78 & 1.628 & & 21.37 & 25.51 & 1.505 & \\
\hline & $+1 \mathrm{CHCl}_{3}$ & 30.63 & 25.87 & 1.647 & 2.022 & 23.55 & 27.91 & 1.516 & 1.965 \\
\hline \multirow{3}{*}{$\begin{array}{l}\text { dichloromethane } \\
\text { acetone } \\
\text { acetonitrile }\end{array}$} & & 31.19 & 26.26 & 1.741 & 2.042 & 23.08 & 27.29 & 1.551 & 1.962 \\
\hline & & 33.37 & 28.25 & 1.846 & 2.113 & 24.32 & 28.63 & 1.588 & 2.000 \\
\hline & & 34.58 & 29.25 & 1.898 & 2.181 & 24.82 & 29.14 & 1.600 & 2.016 \\
\hline \multirow[t]{2}{*}{ methanol } & no H-bonds & 34.57 & 29.24 & 1.898 & & 24.82 & 29.16 & 1.599 & \\
\hline & $+2 \mathrm{CH}_{3} \mathrm{OH}$ & 36.81 & 30.66 & 2.047 & 2.567 & 26.25 & 30.90 & 1.662 & 2.123 \\
\hline \multirow[t]{4}{*}{ water } & no H-bonds & 34.84 & 30.00 & 1.966 & & 25.71 & 30.11 & 1.618 & \\
\hline & $+2 \mathrm{H}_{2} \mathrm{O}$ & 37.38 & 31.27 & 2.122 & 2.799 & 26.17 & 30.91 & 1.691 & 2.132 \\
\hline & $+3 \mathrm{H}_{2} \mathrm{O}$ & 37.36 & 30.96 & 2.176 & & 26.14 & 30.86 & 1.713 & \\
\hline & $+4 \mathrm{H}_{2} \mathrm{O}$ & 37.86 & 31.46 & 2.235 & & 26.81 & 31.57 & 1.755 & \\
\hline
\end{tabular}

${ }^{a}$ From ref 24.

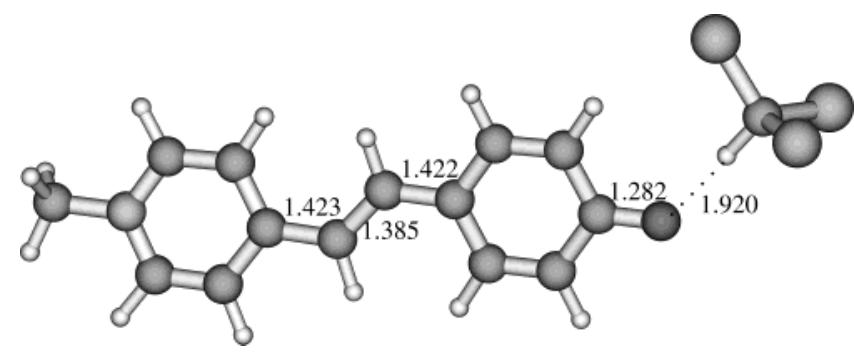

Figure 5. COSMO optimized structure of ground state Brooker's merocyanine $\mathrm{H}$-bonding with one explicit $\mathrm{CHCl}_{3}$ molecule in $\mathrm{CHCl}_{3}$ bulk solution.

vertical excitation energies in the $+3 \mathrm{H}_{2} \mathrm{O}$ and $+4 \mathrm{H}_{2} \mathrm{O}$ models are caused by the increase of the $\Delta E_{0}$ values. Though there is charge redistribution going from the $+2 \mathrm{H}_{2} \mathrm{O}$ to $+3 \mathrm{H}_{2} \mathrm{O}$ and $+4 \mathrm{H}_{2} \mathrm{O}$ models, the dipole moments of $\mu_{\mathrm{S}_{0}}$ and $\mu_{\mathrm{S}_{1}}$ for the three structures are quite similar to each other. However, the molecular structures of the $+3 \mathrm{H}_{2} \mathrm{O}$ and $+4 \mathrm{H}_{2} \mathrm{O}$ models are more polarized. The bond lengths of $\mathrm{C}_{1}-\mathrm{C}_{2}, \mathrm{C}_{3}-\mathrm{C}_{4}$, and $\mathrm{C}_{7}-\mathrm{O}_{8}$ are elongated, and the $\mathrm{C}_{2}=\mathrm{C}_{3}$ bond is shortened. In the $+4 \mathrm{H}_{2} \mathrm{O}$ model, the $\mathrm{H}$-bonding distances of the two water molecules which are in the same plane with the solute are shorter than the other two which are perpendicular to the solute plane (see Figure $3 f$ ).

Comparing the $E_{\mathrm{abs}}\left(\mathrm{H}_{2} \mathrm{O}\right)-E_{\mathrm{abs}}\left(\mathrm{CHCl}_{3}\right)$ values obtained from the SCRF/VSCRF(FDPB) calculations at different geometries, $0.130 \mathrm{eV}$ at the gas-phase geometry, $0.338 \mathrm{eV}$ at COSMO optimized geometries in $\mathrm{CHCl}_{3}$ and $\mathrm{H}_{2} \mathrm{O}$ without explicit $\mathrm{H}_{2} \mathrm{O}$ molecules, and $0.494,0.548$, and $0.607 \mathrm{eV}$ by adding two, three, and four $\mathrm{H}_{2} \mathrm{O}$ molecules for the structure in $\mathrm{H}_{2} \mathrm{O}$ solution, clearly we see that the calculated result is better after relaxing the molecular structures using the COSMO, is improved by adding two explicit $\mathrm{H}$-bonding $\mathrm{H}_{2} \mathrm{O}$ molecules, and is further improved by including three or four $\mathrm{H}$-bonding $\mathrm{H}_{2} \mathrm{O}$ molecules. The best value of $E_{\mathrm{abs}}\left(\mathrm{H}_{2} \mathrm{O}\right)-E_{\mathrm{abs}}\left(\mathrm{CHCl}_{3}\right)=0.607 \mathrm{eV}$ we obtained here is also better than the recent solvaton-CS INDO calculation $(0.525 \mathrm{eV}),{ }^{24}$ where the solute geometry was unchanged in different solvents and no explicit H-bonding interactions were considered.

So far we have only considered the explicit H-bonding effect in water. On the other hand, chloroform may also be considered as a hydrogen bond donor. We therefore added one explicit chloroform molecule (see Figure 5) H-bonding to the oxygen atom. COSMO geometry optimization in bulk $\mathrm{CHCl}_{3}$ shows that the solute structure is a little more polarized by this explicitly interacting $\mathrm{CHCl}_{3}$ molecule. The vertical excitation

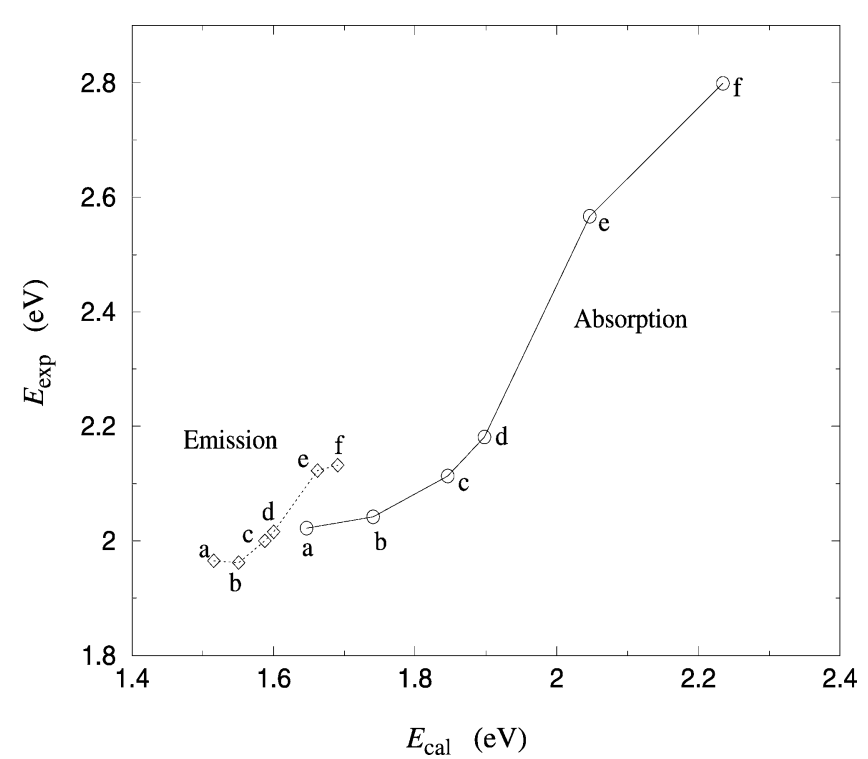

Figure 6. Correlation between the calculated $\left(E_{\text {cal }}\right)$ and observed $\left(E_{\text {exp }}\right)$ absorption ( - with $\bigcirc$ ) and emission ( $\cdots$ with $\diamond)$ energies for Brooker's merocyanine: (a) in chloroform; (b) in dichloromethane; (c) in acetone; (d) in acetonitrile; (e) $+2 \mathrm{CH}_{3} \mathrm{OH}$ in methanol; and (f) $+4 \mathrm{H}_{2} \mathrm{O}$ (for absorption) and $+2 \mathrm{H}_{2} \mathrm{O}$ (for emission) in water. The figure is generated using Xmgr. ${ }^{80}$

energy predicted by the FVSCRF-PB/VSCRF calculations is $1.647 \mathrm{eV}$, which is only $0.019 \mathrm{eV}$ larger than the one without the explicit $\mathrm{CHCl}_{3}$ molecule. We see the explicit $\mathrm{H}$-bonding $\mathrm{H}_{2} \mathrm{O}$ molecules have much larger effects on the solute excitation energies. Now taking $1.647 \mathrm{eV}$ as the solute excitation energy in $\mathrm{CHCl}_{3}$, the blue shifts of absorption spectra from $\mathrm{CHCl}_{3}$ to $\mathrm{H}_{2} \mathrm{O}$ will be $0.475,0.529$, and $0.588 \mathrm{eV}$ for the $+2 \mathrm{H}_{2} \mathrm{O},+3 \mathrm{H}_{2} \mathrm{O}$, and $+4 \mathrm{H}_{2} \mathrm{O}$ models, respectively.

4.2.4. Excitation and Emission Calculations in Different Solvents. We computed both the excitation and emission energies for Brooker's merocyanine in chloroform, dichloromethane, acetone, acetonitrile, methanol, and water. The results are given in Table 5 and Figure 6.

For the absorption process, experimentally the excitation energies are in the order $E_{\text {abs }}$ (chloroform) $<E_{\text {abs }}$ (dichloromethane $)<E_{\text {abs }}$ (acetone) $<E_{\text {abs }}$ (acetonitrile) $<E_{\text {abs }}$ (methanol $)<E_{\mathrm{abs}}$ (water). Except for the relative positions of $E_{\mathrm{abs}}-$ (acetonitrile) and $E_{\mathrm{abs}}$ (methanol), our VSCRF calculations correctly predicted this ordering. Since the dielectric constants of acetonitrile (37.5) and methanol (32.7) are similar to each 
other, the calculations predict the same excitation energy in these two solvents. The larger observed $E_{\text {abs }}$ (methanol) should be caused by the explicit $\mathrm{H}$-bonding effects which make the solute more polarized. Similar to the case of the $+2 \mathrm{H}_{2} \mathrm{O}$ model, we then added two $\mathrm{CH}_{3} \mathrm{OH}$ molecules $\mathrm{H}$-bonding to the oxygen atom of Brooker's merocyanine. The geometry was again optimized using the COSMO. Now we predict $E_{\mathrm{abs}}\left(+2 \mathrm{CH}_{3} \mathrm{OH}\right)$ $=2.047 \mathrm{eV}$, which is $0.149 \mathrm{eV}$ larger than the original value which has no explicit H-bonding interactions. The order $E_{\mathrm{abs}^{-}}$ (acetonitrile) $<E_{\text {abs }}$ (methanol) is, therefore, also achieved.

For the emission process, the solute geometries were optimized in the $\mathrm{S}_{1}^{\prime}$ state. Very similar emission energies for $E_{\mathrm{em}}{ }^{-}$ (chloroform) (1.965 eV) and $E_{\mathrm{em}}$ (dichloromethane) $(1.962 \mathrm{eV})$ have been observed. We predicted a $0.046 \mathrm{eV}$ difference between the two bands. This difference was reduced to 0.035 $\mathrm{eV}$ if the $+1 \mathrm{CHCl}_{3}$ model was used in chloroform. For the corresponding excitation energies, we also predicted a larger blue shift of $E_{\text {abs }}($ dichloromethane $)-E_{\text {abs }}($ chloroform $)=0.113$ $\mathrm{eV}\left(0.094 \mathrm{eV}\right.$ for the $+1 \mathrm{CHCl}_{3}$ model in chloroform). However, the experimental value is only $0.020 \mathrm{eV}$. In a similar way, the energy shifts of $E_{\text {abs(em) }}$ (acetone) $-E_{\text {abs(em) }}$ (chloroform) were also overestimated. It seems that, in the low dielectric region and with moderately increasing solvent polarity, our SCRF/ VSCRF(FDPB) calculations overestimate the increase in polarization. ${ }^{34}$ This will be a subject of further study.

It is also necessary to add explicit $\mathrm{CH}_{3} \mathrm{OH}$ molecules in methanol to get the correct relative fluorescence band positions of $E_{\mathrm{em}}$ (acetonitrile) $<E_{\mathrm{em}}$ (methanol). The experimental emission energies in methanol $(2.123 \mathrm{eV})$ and in water $(2.132 \mathrm{eV})$ are very close to each other. Our models with two to four $\mathrm{H}_{2} \mathrm{O}$ molecules all slightly overestimate the value of $E_{\mathrm{em}}\left(\mathrm{H}_{2} \mathrm{O}\right)-$ $E_{\mathrm{em}}$ (methanol). Since the solute dipole moment decreases upon excitation and further decreases upon $S_{1}$ state geometry relaxation, the dynamically averaged number of explicit $\mathrm{H}$ bonding $\mathrm{H}_{2} \mathrm{O}$ and $\mathrm{CH}_{3} \mathrm{OH}$ molecules in water and methanol will probably decrease. There may be only one or two $\mathrm{H}_{2} \mathrm{O}$ or $\mathrm{CH}_{3}-$ $\mathrm{OH}$ molecules $\mathrm{H}$-bonding to the relaxed $\mathrm{S}_{1}$ state solute. The predicted blue shift of $E_{\mathrm{em}}\left(+2 \mathrm{H}_{2} \mathrm{O}\right)-E_{\mathrm{em}}\left(+1 \mathrm{CHCl}_{3}\right)=0.175$ $\mathrm{eV}$, which is very close to the observed value of $0.167 \mathrm{eV}$ and also better than the corresponding solvation-CS INDO ${ }^{24}$ result of $0.037 \mathrm{eV}$. Overall, our calculations predict the relative excitation and emission energy orderings for Brooker's merocyanine in these solvents with different polarities. Also, the calculated Stokes shift $\left(E_{\mathrm{abs}}-E_{\mathrm{em}}\right)$ is fairly well represented for different solvents, and the calculations correctly show that the absorption energies have a much stronger solvent dependence than the emission energies.

\section{Conclusions}

In this paper, we have presented a density functional vertical self-consistent reaction field (VSCRF) solvation model for studying vertical excitation and emission processes. These methods have been applied to diazines to predict the blue shifts of the UV absorption spectra with increasing solvent polarities from $n$-heptane to water solutions. Our calculations correctly predicted all solvent shift trends in the excitation energies, particularly reproducing the solute absorption energy shifts from $n$-heptane to water very well.

The blue shifts of the excitation and emission bands of Brooker's merocyanine with increasing solvent polarity have also been studied here. Our calculations show that this molecule is also a zwitterion in the nonpolar $\mathrm{CHCl}_{3}$ solvent, which is in agreement with the ${ }^{1} \mathrm{H}$ and ${ }^{13} \mathrm{C}$ NMR experiments. ${ }^{22}$ Even without relaxation of the molecular geometry, the VSCRF calculations can predict the correct trends of solvent dependence of the electronic and energetic properties for Brooker's merocyanine from $\mathrm{CHCl}_{3}$ to $\mathrm{H}_{2} \mathrm{O}$ solution. However, the predicted relative positions of the absorption bands in $\mathrm{CHCl}_{3}$ and in $\mathrm{H}_{2} \mathrm{O}$ give too small a difference for the blue shift. Geometry optimization using the COSMO in the ADF program and adding two, three, or four explicit $\mathrm{H}$-bonding $\mathrm{H}_{2} \mathrm{O}$ molecules to the solute in this study have improved both the absolute and relative vertical excitation energies. The relative excitation and emission energy orderings for Brooker's merocyanine in several other solvents have also been reproduced. It is also necessary to include explicit $\mathrm{H}$-bonding $\mathrm{CH}_{3} \mathrm{OH}$ molecules for the solute in methanol in order to predict correct relative excitation and emission band positions in methanol and in acetonitrile.

Further applications on other solvent-sensitive dyes for both the excitation and emission energy calculations in different solvents have been published very recently. ${ }^{43}$

Acknowledgment. We thank Novartis and the NIH(GM43278 and GM39914 for L.N., W.G.H., and T.L., GM57464 and AG15430 for K.H., and GM45607 for D.B.) for financial support. We are grateful to D. Asthagiri for very useful discussions and help in programming. F.H. would like to thank the Wenner-Gren Foundations for financial support while at The Scripps Research Institute, and A.T. thanks the Leukemia and Lymphoma Society.

\section{References and Notes}

(1) Reichardt, C. Solvent Effects in Organic Chemistry; Verlag Chemie: Weinheim, Germany, 1979.

(2) Hahn, K. M.; Waggoner, A. S.; Taylor, D. L. J. Biol. Chem. 1990, $265,20335-20345$.

(3) Hahn, K.; DeBiasio, R.; Taylor, D. L. Nature 1992, 359, 736738.

(4) (a) Chamberlain, C.; Hahn, K. M. Traffic (Copenhagen) 2000, 1, 755-762. (b) Gaits, F.; Hahn, K. Science's STKE 2003, 3.

(5) Auer, M.; Graf, C.; La Clair, J. J. Angew. Chem., Int. Ed. 2001, $40,1889-1892$.

(6) Turro, N. J. Modern Molecular Photochemistry; University Science Books: Mill Valley, CA, 1991

(7) (a) McRae, E. G. J. Phys. Chem. 1957, 61, 562-572. (b) Lippert, E. Ber. Bunsen-Ges. Phys. Chem. 1957, 61, 962. (c) Basu, S. Adv. Quantum Chem. 1964, 1, 145. (d) Amos, A. T.; Burrows, B. L. Adv. Quantum Chem. 1973, 7, 289.

(8) (a) Rettig, W. J. Mol. Struct. 1982, 84, 303-327. (b) Rettig, W.; Zander, M. Ber. Bunsen-Ges. Phys. Chem. 1983, 87, 1143-1149. (c) Zander, M.; Rettig, W. Chem. Phys. Lett. 1984, 110, 602-610. 7524.

(9) DeBolt, S. E.; Kollman, P. A. J. Am. Chem. Soc. 1990, 112, 7515-

(10) Luzhkov, V.; Warshel, A. J. Am. Chem. Soc. 1991, 113, 44914499.

(11) Benson, H. G.; Murrell, J. N. J. Chem. Soc., Faraday Trans. 2 1972, 68, 137-143

(12) Botrel, A.; Le Beuze, A.; Jacques, P.; Strub, H. J. Chem. Soc., Faraday Trans. 2 1984, 80, 1235-1252.

(13) Aguilar, M. A.; Olivares del Valle, F. J. J. Chem. Phys. 1993, 98 $7375-7384$

(14) Li, J.; Cramer, C. J.; Truhlar, D. G. Int. J. Quantum Chem. 2000 , $77,264-280$

(15) Zeng, J.; Hush, N. S.; Reimers, J. R. J. Chem. Phys. 1993, 99, 1508-1520; J. Phys. Chem. 1996, 100, 9561-9567.

(16) De Almeida, K. J.; Coutinho, K.; De Almeida, W. B.; Rocha, W. R.; Canuto, S. Phys. Chem. Chem. Phys. 2001, 3, 1583-1587.

(17) (a) Karelson, M. M.; Zerner, M. C. J. Phys. Chem. 1992, 96, 69496957. (b) Karelson, M.; Tamm, T.; Zerner, M. C. J. Phys. Chem. 1993, 97, 11901-11907. (c) Rösch, N.; Zerner, M. C. J. Phys. Chem. 1994, 98, 58175823. (d) Pearl, G. M.; Zerner, M. C. J. Am. Chem. Soc. 1999, 121, 399404.

(18) (a) Rauhut, G.; Clark, T.; Steinke, T. J. Am. Chem. Soc. 1993, 115 9174-9181. (b) Hammam, E.; El-Nahas, A. M. J. Phys. Chem. A 1998 102, 9739-9744. (c) Parusel, A. J. Chem. Soc., Faraday Trans. 1998, 94, $2923-2927$.

(19) Urahata, S.; Canuto, S. Int. J. Quantum Chem. 2000, 80, 10621067.

(20) Klamt, A. J. Phys. Chem. 1996, 100, 3349-3353. 
(21) Morley, J. O. THEOCHEM 1994, 301, 191-202.

(22) Morley, J. O.; Morley, R. M.; Docherty, R.; Charlton, M. H. J. Am. Chem. Soc. 1997, 119, 10192-10202.

(23) Morley, J. O.; Morley, R. M.; Fitton, A. L. J. Am. Chem. Soc. 1998, 120, 11479-11488.

(24) Baraldi, I.; Brancolini, G.; Momicchioli, F.; Ponterini, G.; Vanossi, D. Chem. Phys. 2003, 288, 309-325.

(25) Besley, N. A.; Hirst, J. D. J. Phys. Chem. A 1998, 102, $10791-$ 10797.

(26) Serrano-Andrés, L.; Fülscher, M. P.; Karlström, G. Int. J. Quantum Chem. 1997, 65, 167-181.

(27) Liu, Y.-P.; Newton, M. D. J. Phys. Chem. 1995, 99, 12382-12386.

(28) Liu, Y.-P.; Newton, M. D. J. Phys. Chem. 1994, 98, 7162-7169.

(29) Mennucci, B.; Cammi, R.; Tomasi, J. J. Chem. Phys. 1998, 109, 2798-2807.

(30) Cammi, R.; Mennucci, B. J. Phys. Chem. A 2000, 104, 56315637.

(31) Mennucci, B. J. Am. Chem. Soc. 2002, 124, 1506-1515.

(32) Cossi, M.; Barone, V. J. Chem. Phys. 2000, 112, 2427-2435.

(33) Cossi, M.; Rega, N.; Scalmani, G.; Barone, V. J. Chem. Phys. 2001, 114, 5691-5701.

(34) Cossi, M.; Barone, V. J. Chem. Phys. 2001, 115, 4708-4717.

(35) Barone, V.; Palma, A.; Sanna, N. Chem. Phys. Lett. 2003, 381, $451-457$.

(36) Han, W.-G.; Jalkanen, K. J.; Elstner, M.; Suhai, S. J. Phys. Chem. $B$ 1998, 102, 2587-2602.

(37) Tomasi, J.; Persico, M. Chem. Rev. 1994, 94, 2027-2094.

(38) Cramer, C. J.; Truhlar, D. G. Chem. Rev. 1999, 99, 2161-2200.

(39) Orozco, M.; Luque, F. J. Chem. Rev. 2000, 100, 4187-4226.

(40) Klamt, A.; Schuurmann, G. J. Chem. Soc., Perkin Trans. 2 1993, 799-805.

(41) Klamt, A. J. Phys. Chem. 1995, 99, 2224-2235.

(42) Klamt, A.; Jones, V. J. Chem. Phys. 1996, 105, 9972-9981.

(43) Han, W.-G.; Liu, T.; Himo, F.; Toutchkine, A.; Bashford, D.; Hahn,

K. M.; Noodleman, L. ChemPhysChem 2003, 4, 1084-1094.

(44) van Gisbergen, S. J. A.; Groeneveld, J. A.; Rosa, A.; Snijders, J.

G.; Baerends, E. J. J. Phys. Chem. A 1999, 103, 6835-6844.

(45) Han, W.-G.; Lovell, T.; Liu, T.; Noodleman, L. ChemPhysChem 2002, 3, 167-178.

(46) Hu, C.-H.; Chong, D. P. In Encyclopedia of Computational Chemistry; Schleyer, P. von R., Allinger, N. L., Clark, T., Kollman, P. A., Schaefer, H. F., III, Gasteiger, J., Eds.; John Wiley \& Sons Ltd.: Chichester, U.K., 1998; Vol. 1, p 664.

(47) Ziegler, T. Can. J. Chem. 1995, 73, 743-761.

(48) Ziegler, T. Chem. Rev. 1991, 91, 651-667.

(49) Daul, C.; Baerends, E. J.; Vernooijs, P. Inorg. Chem. 1994, 33, $3538-3543$

(50) Doclo, K.; De Corte, D.; Daul, C.; Gudel, H. U. Inorg. Chem. 1998, $37,3842-3847$.

(51) Noodleman, L.; Baerends, E. J. J. Am. Chem. Soc. 1984, 106, 23162327.

(52) Adams, D. M.; Noodleman, L.; Hendrickson, D. N. Inorg. Chem. 1997, 36, 3966-3986.
(53) Han, W.-G.; Suhai, S. J. Phys. Chem. 1996, 100, 3942-3949.

(54) (a) ADF2000.02; Scientific Computing \& Modeling: Amsterdam, The Netherlands, 2000. (b) Te Velde, G.; Bickelhaupt, F. M.; Baerends, E. J.; Guerra, C. F.; Van Gisbergen, S. J. A.; Snijders, J. G.; Ziegler, T. J. Comput. Chem. 2001, 22, 931-967.

(55) Chen, J.; Noodleman, L.; Case, D. A.; Bashford, D. J. Phys. Chem. 1994, 98, 11059-11068.

(56) Bashford, D. Scientific Computing in Object Oriented Parallel Environments (Lecture Nodes in Computer Science); Springer: Berlin, 1997; p 240.

(57) Li, J.; Nelson, M. R.; Peng, C. Y.; Bashford, D.; Noodleman, L. J. Phys. Chem. A 1998, 102, 6311-6324.

(58) Thompson, M. J.; Bashford, D.; Noodleman, L.; Getzoff, E. D. J. Am. Chem. Soc. 2003, 125, 8186-8194.

(59) Thompson, M. J.; Liu, T.; Bashford, D.; Getzoff, E. D.; Noodleman,

L. ChemPhysChem, submitted for publication, 2003.

(60) Sharp, K. A. Biophys. J. 1998, 73, 1241-1250.

(61) Docherty, V. J.; Pugh, D.; Morley, J. O. J. Chem. Soc., Faraday Trans. 2 1985, 81, 1179

(62) Luzhkov, V.; Warshel, A. J. Am. Chem. Soc. 1991, 113, 44914499.

(63) Albert, I. D. L.; Marks, T. J.; Ratner, M. A. J. Phys. Chem. 1996, 100, 9714-9725

(64) Catalán, J.; Mena, E.; Meutermans, W.; Elguero, J. J. Phys. Chem. 1992, 96, 3615-3621.

(65) Catalán, J.; Perez, P.; Elguero, J.; Meutermans, W. Chem. Ber. 1993, $126,2445-2448$.

(66) Asthagiri, D.; Dillet, V.; Liu, T.; Noodleman, L.; Van Etten, R. L.; Bashford, D. J. Am. Chem. Soc. 2002, 124, 10225-10235.

(67) Thompson, M. J. Density Functional Model of Photoactive Yellow Protein. Ph.D. Thesis, The Scripps Research Institute, La Jolla, CA, March 2003, pp 33-39.

(68) Vosko, S. H.; Wilk, L.; Nusair, M. Can. J. Phys. 1980, 58, 12001211 .

(69) Becke, A. D. Phys. Rev. A 1988, 38, 3098.

(70) Perdew, J. P. Phys. Rev. B 1986, 33, 8822-8824; 1986, 34, 7406 (erratum)

(71) Ziegler, T.; Rauk, A.; Baerends, E. J. Theor. Chim. Acta 1977, 43 $261-271$

(72) Ziegler, T. Chem. Rev. 1991, 91, 651-667.

(73) Bashford, D. Curr. Opin. Struct. Biol. 1991, 1, 175.

(74) Bashford, D.; Gerwert, K. J. Mol. Biol. 1992, 224, 473-486. 620

75) Lim, C.; Bashford, D.; Karplus, M. J. Phys. Chem. 1991, 95, 5610-

(76) Bashford, D.; Case, D. A.; Dalvit, C.; Tennant, L.; Wright, P. E. Biochemistry 1993, 32, 8045-8056.

(77) Baba, H.; Goodman, L.; Valenti, P. C. J. Am. Chem. Soc. 1966, $88,5410-5415$

(78) Gibson, H. W.; Bailey, F. C. Tetrahedron 1974, 30, 2043-2051.

(79) Flükiger, P.; Lüthi, H. P.; Portmann, S.; Weber, J. MOLEKEL 4.0;

Swiss Center for Scientific Computing: Manno, Switzerland, 2000

(80) Xmgr V.4.1.2. Copyright 1991-1995 Turner, P. J.; Copyright 1996-1998 ACE/gr Development Team. 